\title{
CONSERVAÇÃO DE SEMENTES DE MARACUJÁ-AMARELO (Passiflora edulis Sims f. flavicarpa Deg.): INTERFERÊNCIAS DO TEOR DE ÁGUA DAS SEMENTES E DA TEMPERATURA DO AMBIENTE
}

\author{
SAMARA CAMARGO LOPES FONSECA
}

\author{
Tese apresentada à Escola Superior de Agricultura \\ “Luiz de Queiroz”, Universidade de São Paulo, para \\ obtenção do título de Doutor em Agronomia, Área de \\ Concentração: Fitotecnia
}

\author{
P I R A C I C A B A \\ Estado de São Paulo - Brasil \\ Março - 2004
}




\title{
CONSERVAÇÃO DE SEMENTES DE MARACUJÁ-AMARELO (Passiflora edulis Sims f. flavicarpa Deg.): INTERFERÊNCIAS DO TEOR DE ÁGUA DAS SEMENTES E DA TEMPERATURA DO AMBIENTE
}

\section{SAMARA CAMARgo LOPES FONSECA}

Bacharel em Ciências Biológicas

Orientador: Prof. Dr. WALTER RODRIGUES DA SILVA

\begin{abstract}
Tese apresentada à Escola Superior de Agricultura “Luiz de Queiroz”, Universidade de São Paulo, para obtenção do título de Doutor em Agronomia, Área de Concentração: Fitotecnia
\end{abstract}

\author{
P I R A C I C A B A \\ Estado de São Paulo - Brasil \\ Março - 2004
}


Dados Internacionais de Catalogação na Publicação (CIP)
DIVISÃO DE BIBLIOTECA E DOCUMENTAÇÃO - ESALQ/USP

Fonseca, Samara Camargo Lopes

Conservação de sementes de maracujá-amarelo (Passiflora edulis Sims f.

flavicarpa Deg.): interferências do teor de água das sementes e da temperatura do ambiente / Samara Camargo Lopes Fonseca. - - Piracicaba, 2004.

$32 \mathrm{p}$.

Tese (doutorado) - Escola Superior de Agricultura Luiz de Queiroz, 2004.

Bibliografia.

1. Armazenamento agrícola 2. Fitotecnia 3. Maracujá-amarelo 4. Sementes 5. Teor de água I.Título

CDD 634.425

"Permitida a cópia total ou parcial deste documento, desde que citada a fonte - O autor" 
À minha mãe (in memoriam) e ao meu pai, por tudo.

Ao meu lindo marido Joelson, Aos nossos pequenos Imirá Lis e Pedro Piá, e ao neném que está por vir, pela energia e pelo carinho a mim retribuídos. 


\section{AGRADECIMENTOS}

Ao Professor Doutor Walter Rodrigues da Silva, pela constante orientação.

Ao Programa de Pós-Graduação em Fitotecnia, pela oportunidade de realização do curso.

À Coordenação de Aperfeiçoamento do Pessoal de Ensino Superior (CAPES), pelo suporte financeiro.

Ao Senhor Antonio Miedis, pela doação dos frutos para a realização da pesquisa.

Ao Instituto Agronômico de Campinas, em especial à Doutora Laura Maria Molina Meletti e à Senhora Maria da Graça, pelo auxilio no processo de extração e limpeza das sementes.

À Engenheira Agrônoma Helena M.C.P. Chamma, pelo auxílio técnico durante a realização da parte experimental.

À Secretária da Tecnologia de Sementes Ilze Helena Cândida de Gaspari das Neves, pela assistência e simpatia.

A todos com quem eu convivi durante a realização do curso, em especial aos colegas Ebert Pepe Obando Flor e Magali A. Oliveira Santos pela colaboração no início do procedimento experimental. 


\section{SUMÁRIO}

\begin{tabular}{|c|c|}
\hline LISTA DE TABELAS.. & vi \\
\hline RESUMO.... & viii \\
\hline SUMMARY ..................... & $\mathrm{x}$ \\
\hline 1 INTRODUÇÃO.............. & 1 \\
\hline 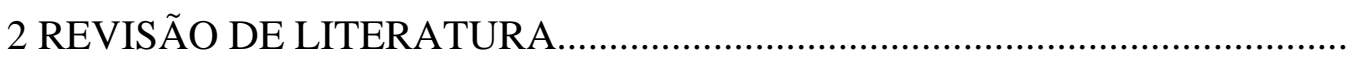 & 3 \\
\hline 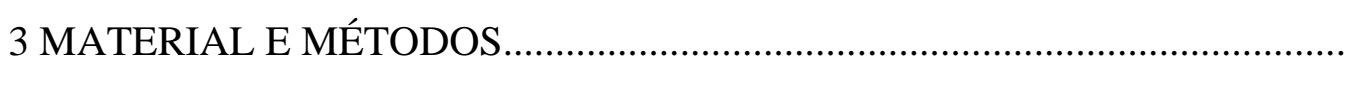 & 6 \\
\hline 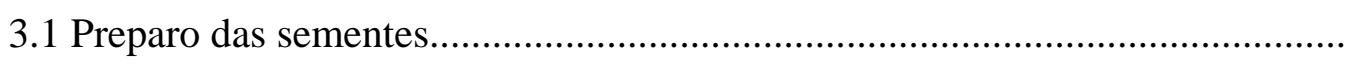 & 6 \\
\hline 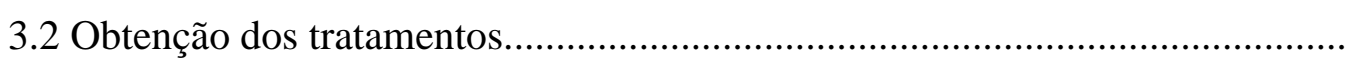 & 6 \\
\hline 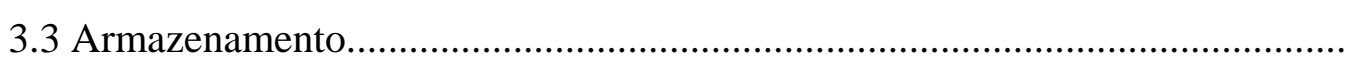 & 7 \\
\hline 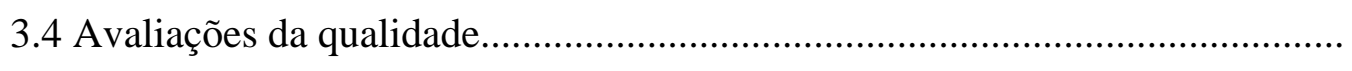 & 7 \\
\hline 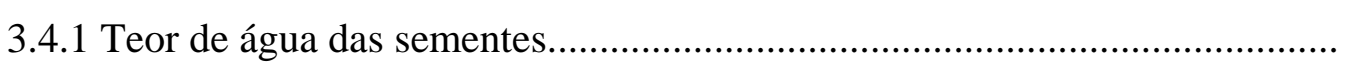 & 7 \\
\hline 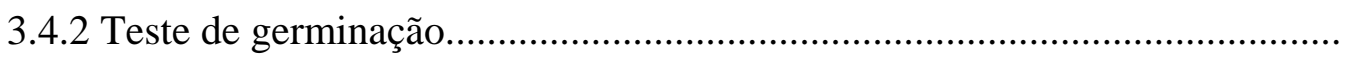 & 8 \\
\hline 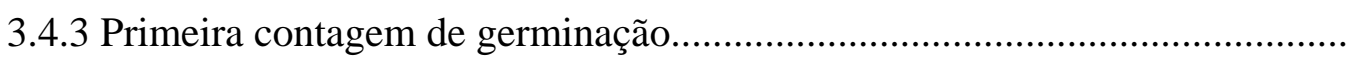 & 8 \\
\hline 3.4.4 Comprimentos de raiz, de hipocótilo e de plântula............................................ & 8 \\
\hline 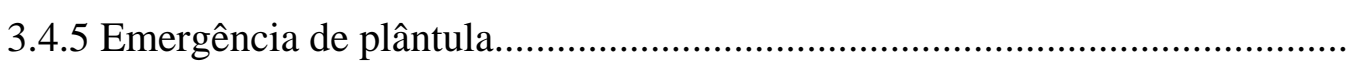 & 8 \\
\hline 3.4.6 Velocidade de emergência de plântula.................................... & 9 \\
\hline 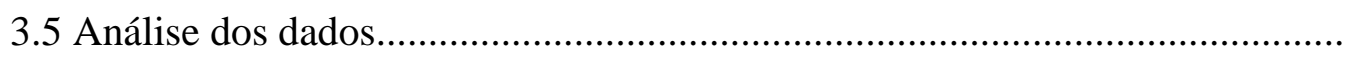 & 9 \\
\hline 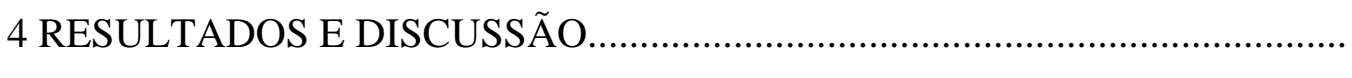 & 13 \\
\hline 5 CONCLUSÕES............................... & \\
\hline REFERÊNCIAS BIBLIOGRÁFICAS.... & \\
\hline
\end{tabular}




\section{LISTA DE TABELAS}

Página

1 Esquema da análise de variância para os dados das avaliações realizadas antes e durante o armazenamento. 9

2 Classificação estatística: exemplo hipotético das pontuações parciais ( $\sum$ das pontuações obtidas nas avaliações fisiológicas por período de armazenamento) e total ( $\sum$ das pontuações parciais) atribuídas aos tratamentos.

3 Classificação absoluta: exemplo hipotético das pontuações parciais ( $\sum$ das pontuações obtidas nas avaliações fisiológicas por período de armazenamento) e total ( $\sum$ das pontuações parciais) atribuídas aos tratamentos........................... 12

4 Teor de água (U), germinação (G), primeira contagem de germinação (PC), emergência de plântula (E), índice de velocidade de emergência de plântula (IVE), comprimento de raiz (R), comprimento de hipocótilo (H) e comprimento de plântula (P) em sementes de maracujá-amarelo: valores médios obtidos antes do armazenamento.

5 Teor de água das sementes de maracujá-amarelo: valores médios (\%, Bu) obtidos durante o armazenamento

6 Germinação das sementes de maracujá-amarelo: valores médios (\%) obtidos durante o armazenamento.

7 Primeira contagem de germinação das sementes de maracujá-amarelo: valores médios (\%) obtidos durante o armazenamento

8 Comprimento de raiz em maracujá-amarelo: valores médios (mm) obtidos durante o armazenamento

9 Comprimento de hipocótilo em maracujá-amarelo: valores médios ( $\mathrm{mm}$ ) obtidos durante o armazenamento. 
10 Comprimento de plântula em maracujá-amarelo: valores médios (mm)

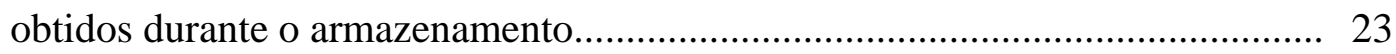

11 Emergência de plântula em maracujá-amarelo: valores médios (\%) obtidos durante o armazenamento................................................................................ 24

12 Índice de velocidade de emergência de plântula em maracujá-amarelo: valores médios obtidos durante $\mathrm{o}$ armazenamento............................................... 25

13 Classificação estatística: pontuações parciais ( $\sum$ das pontuações obtidas nas avaliações fisiológicas por período de armazenamento) e total ( $\sum$ das pontuações parciais) atribuídas aos tratamentos.................................................... 26

14 Classificação absoluta: pontuações parciais ( $\sum$ das pontuações obtidas nas avaliações fisiológicas por período de armazenamento) e total ( $\sum$ das pontuações parciais) atribuídas aos tratamentos.................................................. 


\title{
CONSERVAÇÃO DE SEMENTES DE MARACUJÁ-AMARELO (Passiflora edulis Sims f. flavicarpa Deg.): INTERFERÊNCIAS DO TEOR DE ÁGUA DAS SEMENTES E DA TEMPERATURA DO AMBIENTE
}

\author{
Autora: SAMARA CAMARGO LOPES FONSECA \\ Orientador: Prof. Dr. WALTER RODRIGUES DA SILVA
}

\section{RESUMO}

As sementes de maracujá-amarelo perdem rapidamente o poder germinativo quando são arbitrariamente armazenadas; assim, buscando embasamento para a definição de alternativas tecnológicas voltadas à desaceleração da deterioração durante o armazenamento, o objetivo da pesquisa foi o de estudar, através de variações no teor de água das sementes e na temperatura do ambiente, o comportamento fisiológico de sementes de maracujazeiro. A experimentação, realizada entre julho de 2002 e agosto de 2003 no Laboratório de Análise de Sementes localizado na Escola Superior de Agricultura Luiz de Queiroz/ USP, foi conduzida com sementes de maracujá-amarelo (Passiflora edulis Sims f. flavicarpa Deg.) produzidas em Mogi Mirim/ SP a partir de polinização aleatória entre plantas da Série IAC 270. Após a retirada da mucilagem das sementes, foi determinado o grau de umidade inicial do lote e, paralelamente, obtida a amostra representante do tratamento com o maior teor de água estudado (31\%); as sementes remanescentes foram submetidas à secagem, em estufa com circulação de ar a $30^{\circ} \mathrm{C} \pm 3^{\circ} \mathrm{C}$, para a obtenção dos demais tratamentos referentes aos teores de água desejados (27\%, 21\%, 17\%, 11\% e 7\%). Posteriormente, os tratamentos, correspondentes aos diferentes graus de umidade, foram armazenados em câmaras com temperaturas controladas de $10^{\circ} \mathrm{C}, 15^{\circ} \mathrm{C}$ e $20^{\circ} \mathrm{C}$. Antes do armazenamento, e após 35, 
70, 105, 140, 175, 210, 245, 280, 315 e 350 dias, as sementes foram submetidas às avaliações da qualidade. De acordo com os resultados obtidos, a combinação do grau de umidade de $7 \%$ com a temperatura de $10^{\circ} \mathrm{C}$ supera as demais no favorecimento à manutenção do potencial fisiológico das sementes de Passiflora edulis Sims f. flavicarpa Deg.

Palavras chave: armazenamento agrícola, Fitotecnia, maracujá-amarelo, sementes, teor de água. 


\title{
CONSERVATION OF YELLOW PASSION FRUIT (Passiflora edulis Sims $\mathrm{f}$. flavicarpa Deg.) SEEDS: INTERFERENCE OF WATER CONTENT AND ENVIRONMENT TEMPERATURE
}

\author{
Author: SAMARA CAMARGO LOPES FONSECA \\ Adviser: Prof. Dr. WALTER RODRIGUES DA SILVA
}

SUMMARY

Yellow passion fruit seeds quickly lose the germination capacity when erratically stored; thus, seeding grounds to define technological alternatives to delay deterioration during storage, the goal of this research was to study the physiological behavior of passion fruit (Passiflora edulis Sims f. flavicarpa Deg.) seeds through varied seed water content and environmental temperature. The experiment was conducted at the Seed Analysis Laboratory of the Escola Superior de Agricultura Luiz de Queiroz - USP, from July 2002 through August 2003, with yellow passion fruit seeds produced in Mogi Mirim/ SP, through random pollination among IAC 270 Series plants. Following seed mucilage removal, the initial moisture degree of the lot was determined and the representative sample of the treatment with the highest water content studied (31\%) was obtained concurrently; the remaining seeds were dried in na air-circulating oven at $30^{\circ} \mathrm{C}$ $\pm 3^{\circ} \mathrm{C}$ to achieve other treatments regarding the intended water contents $(27 \%, 21 \%$, $17 \%, 11 \%$ and $7 \%)$. Further, the treatments - corresponding to different moisture levels were stored in controlled-temperature chambers at $10^{\circ} \mathrm{C}, 15^{\circ} \mathrm{C}$ and $20^{\circ} \mathrm{C}$. Previous to storage and 35, 70, 105, 140, 175, 210, 245, 280, 315 and 350 days later, the seeds were submited to quality assays. The results indicate that the combination between $7 \%$ moisture degree and $10^{\circ} \mathrm{C}$ temperature overcomes the remaining ones towards favoring 
the maintenance of the physiological potential of Passiflora edulis Sims f. flavicarpa Deg. seeds.

Key-words: agricultural storage, Fitotecnia, yellow passion fruit, seeds, water content 


\section{INTRODUÇÃO}

A cultura do maracujazeiro amarelo ou azedo (Passiflora edulis Sims f. flavicarpa Deg.) possibilita a obtenção de produtos envolvidos em usos ornamental, farmacológico, e, principalmente, alimentar (Lima, 1993). Representado por 95\% dos pomares comerciais existentes (Sousa \& Meletti, 1997), o Brasil é o maior produtor mundial da fruta; a expansão da cultura, intensificada na década de 70 , promoveu o surgimento de novos campos em diversas regiões brasileiras, particularmente no Estado de Minas Gerais (Lopes, 1996). Entre 1985 e 1988, enquanto a área cultivada aumentou em aproximadamente 200\%, a produção cresceu 257\% (Bruckner \& Picanço, 2001). Dessa maneira, a demanda por tecnologia requereu o desenvolvimento de novos cultivares e, paralelamente, a disponibilidade de mudas qualitativamente aptas a proporcionar, além de adequado estabelecimento no campo, uniformidade no desenvolvimento populacional (Lopes, 1996).

As sementes de maracujá-amarelo deterioram-se rapidamente quando, extraídas do fruto, são arbitrariamente armazenadas (Piza Júnior, 1991). Essa limitação imposta ao período de semeadura pode, eventualmente, concentrar a obtenção de mudas em épocas nem sempre adequadas ao plantio; adicionalmente, a ocorrência de adversidades ambientais, entre a formação e a colheita dos frutos, pode provocar a diminuição na oferta de mudas em virtude das dificuldades de manutenção de estoques reguladores de sementes.

A partir dessa situação, buscando embasamento para a definição de alternativas tecnológicas voltadas à desaceleração da deterioração durante o armazenamento, o objetivo da pesquisa foi o de estudar, através de variações no teor de água das sementes e 
na temperatura do ambiente, o comportamento fisiológico das sementes de maracujáamarelo. 


\section{REVISÃO DE LITERATURA}

A obtenção de mudas vigorosas depende, diretamente, da qualidade das sementes utilizadas que, por sua vez, sofre interferências do período (Toledo \& Marcos Filho, 1977; Zampieri, 1982) e das condições de armazenamento adotados (Geraldi Junior, 1974; Thai, 1977; Toledo \& Marcos Filho, 1977; Almeida, 1985; São José, 1987; Nakagawa et al., 1991). Na maioria das espécies, as sementes podem ser secadas sem perdas apreciáveis de vigor (Toledo \& Marcos Filho, 1977), havendo casos em que o potencial fisiológico, durante o armazenamento, é mais afetado pelo grau de umidade das sementes do que pelos métodos de secagem a que foram submetidas (Araújo et al., 1989; Barboza \& Herrera, 1990; Vasconcelos et al., 1992). Sementes ortodoxas, armazenadas com teores elevados de água, tendem a deteriorar-se rapidamente em virtude da intensificação da atividade respiratória, do consumo de reservas, da liberação de calor e, conseqüentemente, do estabelecimento de ambiente propício ao aparecimento de agentes patogênicos (Aguiar et al., 1993).

Relacionando a longevidade com o teor de água, Piza Júnior (1991) verificou que as sementes de maracujá-amarelo sofrem dessecação e, gradativamente, perdem o poder germinativo até o quinto mês; a partir de então, a deterioração é acelerada chegando a anular a germinação aos 360 dias de armazenamento. De acordo com Meletti et al. (2002), sementes, que apresentavam 95\% de germinação aos 30 dias de armazenamento, tiveram a viabilidade reduzida para 58\% aos 180 dias. Thai (1977), mantendo sementes com 9,1\% de umidade sob ambiente a $10^{\circ} \mathrm{C}$, obteve $72 \%$ de germinação após um ano; na mesma temperatura de armazenamento, sementes com 5,2\% de umidade perderam a viabilidade aos dez meses. 
A temperatura ambiental, isoladamente ou em associação com a umidade relativa do ar, interfere na conservação das sementes de maracujá-amarelo; há evidências de vantagens do armazenamento em ambiente controlado na comparação com o natural (Geraldi Junior, 1974; Thai, 1977; Becwar et al., 1983; Almeida, 1985; São José, 1987). Segundo Costa et al. (1974), o período de armazenamento, em ambiente sem controle térmico, não deve ser superior a oito meses para garantir, no mínimo, 50\% de germinabilidade; sob ambiente natural, sementes inicialmente com 85\% de germinação apresentaram, após um ano de armazenamento, viabilidade inferior a 25\% (Esquivel \& Labrador, 1977 citando Chapman, 1962). Sementes armazenadas, em ambiente natural e em câmaras seca (45\%UR) ou fria $\left(5^{\circ} \mathrm{C}\right)$, mantiveram-se vigorosas durante seis meses; aos 12 meses, entretanto, as sementes mantidas em ambiente natural perderam a viabilidade, enquanto as conservadas nas câmaras seca ou fria apresentaram, respectivamente, 63 e 82\% de germinação (Almeida et al., 1988). Ao final de 18 meses de armazenamento em ambiente natural e em câmara seca (30-40\%UR), Geraldi Junior (1974) obteve, respectivamente, $16,5 \%$ e $31,5 \%$ de germinabilidade; contudo, a viabilidade das sementes armazenadas em câmara seca foi conservada, por Oliveira et al. (1984), durante cinco anos. Por outro lado, as sementes podem ser satisfatoriamente conservadas em sacos de papel embalados em sacos plásticos, hermeticamente fechados, em ambiente mantido a $10^{\circ} \mathrm{C}$ (Carvalho, 1974); sob $4^{\circ} \mathrm{C}$, Lima et al. (1992) mantiveram a viabilidade das sementes empregando recipientes metálicos herméticos.

A germinação no maracujazeiro é negativamente influenciada pela possível ação de substâncias reguladoras de crescimento presentes no arilo que envolve as sementes; aliado ao fato de contribuir para uma germinação desuniforme, o arilo deve ser adequadamente retirado visando, além da obtenção da máxima germinação, a emergência rápida das plântulas (Pereira \& Dias, 2000). Adicionalmente, conforme relatado por Meletti et al. (2002), a semente recém-colhida apresenta um tipo de dormência temporária, que tem sido superada com o armazenamento por 30 a 40 dias; esse período de armazenamento, que varia de região para região, em geral possibilita a obtenção de índices de germinação superiores a 95\%, valor que decresce, cerca de $8 \%$ ao mês, com o prosseguimento da armazenagem. Outras espécies do gênero Passiflora apresentam um 
período de dormência longo, sendo necessários mais de dois anos de armazenamento para serem obtidos índices satisfatórios de germinação (Meletti et al., 2003).

O armazenamento de sementes, constituído por um conjunto de procedimentos voltados à preservação da qualidade do produto, atua como instrumento para a formação de estoques reguladores e para a manutenção de recursos genéticos através dos bancos de germoplasma (Aguiar et al., 1993); entretanto, os trabalhos disponíveis a respeito da conservação das sementes de maracujá-amarelo, além de escassos, não permitem o estabelecimento de tecnologias de armazenamento alicerçadas no conhecimento científico existente. 


\section{MATERIAL E MÉTODOS}

A experimentação foi conduzida com sementes de maracujá-amarelo (Passiflora edulis Sims f. flavicarpa Deg.), obtidas a partir de polinização aleatória entre plantas da Série IAC 270, produzidas em Mogi Mirim/ SP.

\subsection{Preparo das sementes}

As sementes, recém-extraídas de frutos maduros, foram submetidas à extração parcial da mucilagem em equipamento, existente no Instituto Agronômico de Campinas/ SP, adaptado a partir da substituição das lâminas, em um liqüidificador convencional, por turbilhonador de ação centrífuga sobre a água. O material obtido foi manualmente friccionado contra peneira (arame trançado) de malha inferior ao tamanho das sementes e, posteriormente, lavado em água corrente objetivando a redução da quantidade de mucilagem restante. Em seguida, foi realizada secagem à sombra até a eliminação da água aderida externamente às sementes.

\subsection{Obtenção dos tratamentos}

Primeiramente, foi realizada a determinação do grau de umidade do lote (Brasil, 1992) e, paralelamente, obtida a amostra representante do tratamento com o maior teor de água a ser estudado (31\%). As sementes remanescentes foram submetidas à secagem, em estufa com circulação de ar a $30^{\circ} \mathrm{C} \pm 5^{\circ} \mathrm{C}$, para a obtenção dos demais graus de umidade desejados $(27 \%, 21 \%, 17 \%, 11 \%$ e $7 \%)$. Os tratamentos foram obtidos através do acompanhamento da perda de peso das sementes durante a secagem; para tanto, amostras de sementes para o monitoramento, com pesos iniciais previamente conhecidos, foram acondicionadas em sacos de filó e distribuídas nas bandejas da estufa para pesagens a 
intervalos regulares. Os pesos finais das amostras, correspondentes a cada um dos teores de água desejados, foram estimados através do uso da equação descrita por Cromarty et al. (1985):

$$
\mathrm{Pf}=\mathrm{Pi}(100-\mathrm{Ui}) \times(100-\mathrm{Uf})^{-1}
$$

onde:

$\mathrm{Pf}=$ peso da amostra $(\mathrm{g})$ após a secagem

$\mathrm{Pi}=$ peso da amostra $(\mathrm{g})$ antes da secagem

$\mathrm{Ui}=$ grau de umidade $(\%)$ antes da secagem

Uf = grau de umidade (\%) desejado após a secagem

À medida que foram sendo atingidos graus de umidade próximos aos desejados, amostras foram retiradas, homogeneizadas e divididas em frações que, por sua vez, foram embaladas hermeticamente em sacos transparentes de polietileno $(0,14 \mathrm{~mm}$ de espessura) e mantidas a $10^{\circ} \mathrm{C}$ até a obtenção dos demais tratamentos, concluída 20 horas após o início do processo de secagem.

\subsection{Armazenamento}

Os tratamentos, correspondentes aos diferentes graus de umidade, foram armazenados em câmaras com temperaturas controladas de $10^{\circ} \mathrm{C}, 15^{\circ} \mathrm{C}$ e $20^{\circ} \mathrm{C}$. Antes do armazenamento, e após 35, 70, 105, 140, 175, 210, 245, 280, 315 e 350 dias, as sementes foram submetidas às avaliações da qualidade.

\subsection{Avaliações da qualidade}

\subsubsection{Teor de água das sementes}

Foi determinado a $105^{\circ} \mathrm{C} \pm 3^{\circ} \mathrm{C} / 24 \mathrm{~h}$, pelo método da estufa (Brasil, 1992), em duas amostras de 50 sementes/ repetição. Os dados obtidos, com base no peso úmido $\mathrm{Bu})$, foram expressos em porcentagem. 


\subsubsection{Teste de germinação}

Foram instaladas 50 sementes/ repetição em rolos de papel toalha, umedecidos em volume de água equivalente a 2,5 vezes o seu peso sem a hidratação, mantidos sob temperatura alternada de $20-30^{\circ} \mathrm{C}$ (Brasil, 1992). As avaliações, totalizadas aos 28 dias da instalação do teste, forneceram dados expressos em porcentagem de plântulas normais classificadas segundo os critérios estabelecidos por Pereira \& Andrade (1994).

\subsubsection{Primeira contagem de germinação}

Realizada conjuntamente com o teste de germinação, considerou a contagem do número de plântulas normais aos 21 dias após a semeadura na avaliação realizada antes do armazenamento e, aos 14 dias, nas demais determinações efetuadas durante o armazenamento.

\subsubsection{Comprimentos de raiz, de hipocótilo e de plântula}

De modo similar ao descrito no teste de germinação, 10 sementes/ repetição foram instaladas em rolos de papel toalha mantidos sob temperatura alternada de 20$30^{\circ} \mathrm{C}$. Aos 21 dias após a instalação do teste, foram tomadas as distâncias (mm) do ápice da raiz à região de transição com o hipocótilo (comprimento de raiz) e desta à região de inserção das folhas cotiledonares (comprimento de hipocótilo); a soma de ambas as medidas representou o comprimento de plântula. Os dados médios foram obtidos, em cada uma das determinações, pelo quociente entre o somatório das medidas registradas e o número de sementes utilizadas.

\subsubsection{Emergência de plântula}

Empregando substrato de vermiculita expandida (grão médio) com disponibilidade hídrica mantida próxima à da capacidade de campo, foram semeadas (1cm de profundidade) 50 sementes/ repetição em ambiente sombreado desprovido de controles de temperatura e de umidade relativa. Foram consideradas as plântulas que, 28 dias após a instalação do teste, apresentaram a parte aérea exposta acima da superfície do substrato. Os dados obtidos foram expressos em porcentagem. 


\subsubsection{Velocidade de emergência de plântula}

Foi obtida, a partir da contagem do número diário de indivíduos emersos no teste de emergência de plântula, através do cálculo de índice seguindo os procedimentos descritos por Marcos Filho et al. (1987).

\subsection{Análise dos dados}

O delineamento experimental adotado foi o inteiramente casualizado, com quatro repetições, considerando seis tratamentos (teores de água) antes do armazenamento e 18 tratamentos (seis teores de água $\mathrm{x}$ três temperaturas de armazenamento) em cada época de avaliação durante o armazenamento (Tabela 1). Os dados de germinação, de primeira contagem de germinação e de emergência de plântula foram transformados em arco seno $(\mathrm{x} \% / 100)^{1 / 2}$; os de teor de água não foram submetidos à análise estatística. As médias foram comparadas pelo teste de Tukey ao nível de 5\% de probabilidade.

Tabela 1. Esquema da análise de variância para os dados das avaliações realizadas antes e durante $\mathrm{o}$ armazenamento

\begin{tabular}{lll}
\hline Causas de variação & \multicolumn{2}{c}{ Graus de liberdade } \\
& antes do armazenamento & durante o armazenamento \\
\hline Tratamento & 5 & 17 \\
Resíduo & 18 & 54 \\
Total & 23 & 71 \\
\hline
\end{tabular}

Posteriormente, os tratamentos receberam pontuações conforme a ordenação hierárquica de desempenho verificada em cada avaliação fisiológica. Para tanto, foram consideradas classificações, semelhantes às empregadas por Caliari \& Silva (2001), fundamentadas no teste de Tukey (classificação estatística) e nos valores absolutos (classificação absoluta).

Na classificação estatística (Tabela 2), dentro de cada avaliação fisiológica, foi 
atribuída a cada um dos tratamentos a pontuação resultante do somatório das pontuações positivas ou nulas (número de tratamentos estatisticamente inferiores) com as negativas ou nulas (número de tratamentos estatisticamente superiores). Na classificação absoluta (Tabela 3), a pontuação foi representada pelo número (nulo ou positivo) de tratamentos superados em valor absoluto, independentemente das indicações estatísticas. Em ambas as classificações, o somatório dos valores obtidos em todas as avaliações constituiu a pontuação parcial do tratamento em cada período estudado; a pontuação total resultou do somatório das pontuações parciais (Tabelas 2 e 3). 
Tabela 2. Classificação estatística: exemplo hipotético das pontuações parciais ( $\sum$ das pontuações obtidas nas avaliações fisiológicas por período de armazenamento) e total ( $\sum$ das pontuações parciais) atribuídas aos tratamentos

\begin{tabular}{|c|c|c|c|c|c|c|c|c|c|c|c|}
\hline \multirow[b]{3}{*}{ Tratamentos } & \multicolumn{5}{|c|}{ Período A de armazenamento } & \multicolumn{5}{|c|}{ Período B de armazenamento } & \multirow{3}{*}{$\begin{array}{l}\text { pontuação } \\
\text { total }\end{array}$} \\
\hline & \multirow{2}{*}{\multicolumn{2}{|c|}{$\begin{array}{l}\text { Avaliação x } \\
\text { dados pontos }\end{array}$}} & \multicolumn{2}{|c|}{ Avaliação y } & \multirow{2}{*}{$\begin{array}{l}\text { pontuação } \\
\text { parcial }\end{array}$} & \multicolumn{2}{|c|}{ Avaliação x } & \multicolumn{2}{|c|}{ Avaliação y } & \multirow{2}{*}{$\begin{array}{l}\text { pontuação } \\
\text { parcial }\end{array}$} & \\
\hline & & & dados & pontos & & dados & pontos & dados & pontos & & \\
\hline 1 & $100 a$ & $2+0=2$ & $98 \mathrm{~b}$ & $1+(-1)=0$ & 2 & $96 a$ & $2+0=2$ & $90 \mathrm{bc}$ & $0+(-2)=-2$ & 0 & 2 \\
\hline 2 & 99ab & $1+0=1$ & 97bc & $0+(-1)=-1$ & 0 & $86 c$ & $0+(-4)=-4$ & $97 a$ & $2+0=2$ & -2 & -2 \\
\hline 3 & 90abc & $0+0=0$ & $100 a$ & $3+0=3$ & 3 & $94 a$ & $2+0=2$ & $95 a$ & $2+0=2$ & 4 & 7 \\
\hline 4 & 89bc & $0+(-1)=-1$ & $96 c$ & $0+(-3)=-3$ & -4 & $90 \mathrm{~b}$ & $1+(-2)=-1$ & $92 \mathrm{ab}$ & $1+0=1$ & 0 & -4 \\
\hline 5 & $87 c$ & $0+(-2)=-2$ & 99ab & $1+0=1$ & -1 & $92 \mathrm{ab}$ & $1+0=1$ & $86 c$ & $0+(-3)=-3$ & -20 & -3 \\
\hline
\end{tabular}


Tabela 3. Classificação absoluta: exemplo hipotético das pontuações parciais ( $\sum$ das pontuações obtidas nas avaliações fisiológicas por período de armazenamento) e total ( $\sum$ das pontuações parciais) atribuídas aos tratamentos

\begin{tabular}{|c|c|c|c|c|c|c|c|c|c|c|c|}
\hline \multirow[b]{3}{*}{ Tratamentos } & \multicolumn{5}{|c|}{ Período A de armazenamento } & \multicolumn{5}{|c|}{ Período B de armazenamento } & \multirow{3}{*}{$\begin{array}{l}\text { pontuação } \\
\text { total }\end{array}$} \\
\hline & \multicolumn{2}{|c|}{ Avaliação x } & \multicolumn{2}{|c|}{ Avaliação y } & \multirow{2}{*}{$\begin{array}{l}\text { pontuação } \\
\text { parcial }\end{array}$} & \multicolumn{2}{|c|}{ Avaliação x } & \multicolumn{2}{|c|}{ Avaliação y } & \multirow{2}{*}{$\begin{array}{l}\text { pontuação } \\
\text { parcial }\end{array}$} & \\
\hline & dados & pontos & dados & pontos & & dados & pontos & dados & pontos & & \\
\hline 1 & 100 & 4 & 98 & 2 & 6 & 96 & 4 & 90 & 1 & 5 & 11 \\
\hline 2 & 99 & 3 & 97 & 1 & 4 & 86 & 0 & 97 & 4 & 4 & 8 \\
\hline 3 & 90 & 2 & 100 & 4 & 6 & 94 & 3 & 95 & 3 & 6 & 12 \\
\hline 4 & 89 & 1 & 96 & 0 & 1 & 90 & 1 & 92 & 2 & 3 & 4 \\
\hline 5 & 87 & 0 & 99 & 3 & 3 & 92 & 2 & 86 & 0 & 2 & 5 \\
\hline
\end{tabular}




\section{RESULTADOS E DISCUSSÃO}

Os dados de teor de água obtidos antes do armazenamento (Tabela 4), compatíveis com os desejados, indicaram eficiência do método de acompanhamento da secagem para a obtenção dos tratamentos. Adicionalmente, durante o armazenamento (Tabela 5), foi observada estabilidade para o grau de umidade, dentro de cada tratamento, representada por desvios máximos de 0,9\% entre os dados extremos; dessa forma, a embalagem utilizada, além de proporcionar eficiência na manutenção da umidade dos tratamentos, permitiu confiabilidade nas comparações realizadas durante o armazenamento.

Anteriormente ao armazenamento (Tabela 4), os tratamentos não apresentaram diferenças estatisticamente significativas na germinação e no vigor, indicando ausência de efeitos imediatos do processo de secagem sobre o desempenho fisiológico das sementes. Esse comportamento, independentemente da temperatura empregada no armazenamento, permaneceu inalterado na germinação (Tabela 6) durante 35 dias; a partir de 70 dias, entretanto, diferenças no desempenho entre os tratamentos foram sendo paulatinamente acentuadas no decorrer do período estudado.

No ambiente a $10^{\circ} \mathrm{C}$ (Tabela 6), as sementes com 31\% e 27\% de água foram as únicas a ter a germinação anulada e, juntamente com as de $21 \%$, tenderam a apresentar valores absolutos inferiores aos dos demais tratamentos; a superioridade dos tratamentos com 17\%, 11\% e 7\% de umidade, estabelecida em relação aos de maior umidade, foi constantemente confirmada, em termos estatísticos, a partir de 280 dias de armazenamento. Considerando o período compreendido entre 105 e 210 dias de armazenamento, os tratamentos com 27\% e 21\% de água, de modo isolado, apresentaram comportamento sugestivo do surgimento e da superação seqüenciais de dormência; o 
método adotado, porém, não permitiu aferir a validade dessa hipótese. Similarmente, Almeida (1985) e Medina (1980), citados por Catunda et al. (2003), observaram aumento na germinação após, respectivamente, seis e 12 meses de armazenamento, atribuível à superação de um provável estado de dormência das sementes.

Sob $15^{\circ} \mathrm{C}$ (Tabela 6), o comportamento germinativo dos tratamentos assemelhou-se ao observado a $10^{\circ} \mathrm{C}$. Contudo, a superioridade estatística para a germinação, atribuída aos tratamentos com grau de umidade igual ou inferior a $17 \%$, foi antecipada e permanentemente verificada a partir de 175 dias experimentais.

A germinação (Tabela 6), no ambiente a $20^{\circ} \mathrm{C}$, deixou de ser anulada nas sementes com $27 \%$ de umidade. Porém, quando comparados entre si, os tratamentos mantiveram, aproximadamente, o mesmo comportamento observado a $10^{\circ} \mathrm{C}$ e a $15^{\circ} \mathrm{C}$. A superioridade estatística dos tratamentos com menores teores de água (17\%, 11\% e 7\%), por sua vez, foi menos evidente ao estabelecer-se, de modo definitivo, somente após 315 dias de armazenamento. Similarmente ao verificado a $10^{\circ} \mathrm{C}$, os tratamentos com $27 \%$ e 21\% de água apresentaram variações nos dados, entre 105 e 210 dias de armazenamento, passíveis de atribuição ao fenômeno de dormência.

A redução da temperatura, ao influenciar as atividades metabólicas das sementes, resulta no favorecimento das condições de armazenamento e, conseqüentemente, na conservação da sua qualidade (Toledo \& Marcos Filho, 1977). Contudo, fixados os graus de umidade, diferenças relativas às temperaturas foram esparsas e não permitiram a identificação de tendências consistentes. Por outro lado, fixadas as temperaturas de armazenamento, as sementes com grau de umidade superior a 17\% tenderam a demonstrar, com o progresso do período de armazenamento, redução acentuada no desempenho germinativo; as sementes não secadas (31\% de água) apresentaram, a partir de 140 dias de armazenamento, desempenho predominantemente inferior ao das sementes submetidas à secagem, corroborando os dados obtidos por Almeida (1985) e por São José \& Nakagawa (1988); porém, somente a dessecação a teor de água igual ou inferior a $17 \%$ conservou adequadamente o poder germinativo durante o período estudado. 
A deterioração manifesta-se nas sementes através de alterações químicas e fisiológicas; a perda da capacidade germinativa, observada no teste de germinação, é uma de suas manifestações finais (Toledo \& Marcos Filho, 1977) e portanto, em estudos comparativos, faz-se necessária a realização de testes auxiliares capazes de identificar a deterioração em estádios anteriores. Assim, complementando os dados obtidos na germinação, foi estimado o vigor das sementes através de testes que forneceram os dados a seguir discutidos.

Nos ambientes a $10^{\circ} \mathrm{C}$ e a $15^{\circ} \mathrm{C}$, a análise dos dados de primeira contagem de germinação (Tabela 7) apontou, a partir de 280 dias de armazenamento, superioridade permanente dos tratamentos com teor de água igual ou inferior a 17\% em relação aos demais. Superioridade equivalente, excetuando a similaridade comportamental para o comprimento de raiz a $10^{\circ} \mathrm{C}$ entre os tratamentos com $21 \%$ e $17 \%$ de água aos 350 dias (Tabela 8), foi observada para os comprimentos de raiz (Tabela 8), de hipocótilo (Tabela 9) e de plântula (Tabela 10) a partir de 280 dias de armazenamento. Nos testes de emergência de plântula (Tabela 11) e de velocidade de emergência (Tabela 12), a partir dos 210 dias de armazenamento, a superioridade observada nos demais testes tendeu a ficar restrita aos tratamentos com $11 \%$ e $7 \%$ de água uma vez que, na maior parte dos casos, o tratamento com grau de umidade de $17 \%$ teve desempenho equivalente ao de $21 \%$.

Sob $20^{\circ} \mathrm{C}$, os dados da primeira contagem de germinação (Tabela 7) forneceram indicações similares às observadas nas demais temperaturas, destacando a superioridade dos tratamentos portadores dos menores teores de água (17\%, 11\% e 7\%) a partir de 140 dias de armazenamento. Os testes de comprimentos de raiz (Tabela 8), de hipocótilo (Tabela 9) e de plântula (Tabela 10), por sua vez, detectaram a referida superioridade, mais tardiamente, aos 350 dias de armazenamento. Nos testes de emergência de plântula (Tabela 11) e de velocidade de emergência (Tabela 12), os dados não originaram indicações estatísticas suficientes para proporcionar consistência à sua interpretação; contudo, considerados os valores absolutos observados, a superioridade dos tratamentos com teor de água igual ou inferior a 17\% predominou durante o armazenamento. 
Os resultados verificados nas avaliações fisiológicas, evidenciando a interferência do teor de água na deterioração das sementes, detectaram os valores iguais ou inferiores a $17 \%$ de água como favoráveis à conservação independentemente da temperatura de armazenamento. Contudo, o método de interpretação empregado, considerando os testes isoladamente, acarretou dificuldades para a identificação da combinação específica, entre teor de água e temperatura, mais vantajosa à manutenção do desempenho fisiológico das sementes. Na busca desse esclarecimento, os dados obtidos nos testes fisiológicos foram conjuntamente interpretados, através da atribuição de pontuações aos tratamentos, utilizando os critérios de classificações estatística (Tabela 13) e absoluta (Tabela 14) aplicados por Caliari \& Silva (2001).

Em ambas as classificações, foi confirmada a superioridade dos tratamentos com graus de umidade de $17 \%, 11 \%$ e $7 \%$; entre esses, dentro de cada temperatura, o tratamento com 7\% de água destacou-se invariavelmente como superior aos demais. Adicionalmente, realizando comparações entre as pontuações de todas as combinações (teores de água e temperaturas) estudadas, $7 \%$ de água associado a $10^{\circ} \mathrm{C}$ apresentou a maior pontuação total e constituiu a condição mais favorável à conservação das sementes. 
Tabela 4. Teor de água (U), germinação (G), primeira contagem de germinação (PC), emergência de plântula (E), índice de velocidade de emergência de plântula (IVE), comprimento de raiz (R), comprimento de hipocótilo (H) e comprimento de plântula (P) em sementes de maracujá-amarelo: valores médios ${ }^{1}$ obtidos antes do armazenamento

\begin{tabular}{llllllll}
\hline $\mathrm{U}(\%, \mathrm{Bu})$ & $\mathrm{G}(\%)$ & PC (\%) & E (\%) & IVE & R (mm) & H (mm) & P (mm) \\
\hline 31,3 & $98 \mathrm{a}$ & $95 \mathrm{a}$ & $09 \mathrm{a}$ & $0,10 \mathrm{a}$ & $81 \mathrm{a}$ & $68 \mathrm{a}$ & $149 \mathrm{a}$ \\
26,8 & $97 \mathrm{a}$ & $94 \mathrm{a}$ & $11 \mathrm{a}$ & $0,13 \mathrm{a}$ & $81 \mathrm{a}$ & $64 \mathrm{a}$ & $145 \mathrm{a}$ \\
20,9 & $97 \mathrm{a}$ & $94 \mathrm{a}$ & $10 \mathrm{a}$ & $0,11 \mathrm{a}$ & $82 \mathrm{a}$ & $65 \mathrm{a}$ & $147 \mathrm{a}$ \\
16,6 & $95 \mathrm{a}$ & $92 \mathrm{a}$ & $12 \mathrm{a}$ & $0,16 \mathrm{a}$ & $83 \mathrm{a}$ & $76 \mathrm{a}$ & $159 \mathrm{a}$ \\
10,8 & $93 \mathrm{a}$ & $93 \mathrm{a}$ & $14 \mathrm{a}$ & $0,18 \mathrm{a}$ & $94 \mathrm{a}$ & $72 \mathrm{a}$ & $166 \mathrm{a}$ \\
7,3 & $94 \mathrm{a}$ & $92 \mathrm{a}$ & $15 \mathrm{a}$ & $0,19 \mathrm{a}$ & $93 \mathrm{a}$ & $77 \mathrm{a}$ & $170 \mathrm{a}$ \\
\hline
\end{tabular}

1. Médias seguidas pela mesma letra, na coluna, não diferem entre si pelo teste de Tukey a 5\% de probabilidade. 
Tabela 5. Teor de água das sementes de maracujá-amarelo: valores médios (\%, Bu) obtidos durante o armazenamento

\begin{tabular}{|c|c|c|c|c|c|c|c|c|c|c|}
\hline \multirow{2}{*}{$\begin{array}{l}\text { Tratamentos } \\
\text { (temperatura/ } \\
\text { teor de água) }\end{array}$} & \multicolumn{10}{|c|}{ Período de armazenamento (dias) } \\
\hline & 35 & 70 & 105 & 140 & 175 & 210 & 245 & 280 & 315 & 350 \\
\hline $10^{\circ} \mathrm{C} / 31 \%$ & 31,1 & 31,3 & 30,9 & 31,0 & 31,2 & 31,2 & 31,0 & 31,3 & 31,1 & 30,9 \\
\hline $27 \%$ & 26,9 & 27,0 & 26,8 & 26,8 & 26,7 & 26,6 & 26,9 & 27,0 & 27,1 & 26,9 \\
\hline $21 \%$ & 20,8 & 21,1 & 20,9 & 20,8 & 20,9 & 21,1 & 21,0 & 21,3 & 21,1 & 21,0 \\
\hline $17 \%$ & 16,5 & 16,4 & 16,7 & 17,0 & 16,9 & 16,9 & 16,7 & 16,8 & 16,5 & 16,4 \\
\hline $11 \%$ & 11,0 & 10,8 & 11,1 & 10,9 & 11,1 & 10,8 & 10,6 & 10,5 & 10,7 & 11,0 \\
\hline $7 \%$ & 7,2 & 7,0 & 7,0 & 7,1 & 7,3 & 7,2 & 7,4 & 7,6 & 7,5 & 7,7 \\
\hline $15^{\circ} \mathrm{C} / 31 \%$ & 31,1 & 31,0 & 30,9 & 30,8 & 30,9 & 31,0 & 31,2 & 31,4 & 31,3 & 31,1 \\
\hline $27 \%$ & 27,0 & 26,8 & 26,7 & 27,1 & 26,8 & 27,0 & 27,1 & 26,9 & 27,2 & 26,9 \\
\hline $21 \%$ & 21,1 & 20,8 & 21,0 & 21,1 & 20,9 & 21,0 & 20,7 & 21,3 & 21,1 & 21,0 \\
\hline $17 \%$ & 16,4 & 16,5 & 16,7 & 16,6 & 17,0 & 17,1 & 16,8 & 16,4 & 16,7 & 16,3 \\
\hline $11 \%$ & 10,8 & 11,0 & 11,2 & 10,9 & 10,9 & 11,0 & 11,1 & 10,7 & 10,5 & 11,0 \\
\hline $7 \%$ & 7,0 & 7,2 & 7,2 & 7,5 & 7,3 & 7,4 & 7,2 & 6,6 & 7,1 & 7,5 \\
\hline $20^{\circ} \mathrm{C} / 31 \%$ & 31,0 & 30,9 & 30,8 & 31,1 & 30,8 & 30,9 & 31,2 & 31,4 & 31,3 & 31,0 \\
\hline $27 \%$ & 26,8 & 26,9 & 26,6 & 26,6 & 26,4 & 26,7 & 26,9 & 27,1 & 27,0 & 26,8 \\
\hline $21 \%$ & 20,8 & 20,7 & 20,9 & 21,0 & 21,2 & 20,8 & 21,0 & 21,4 & 21,1 & 20,9 \\
\hline $17 \%$ & 16,5 & 16,7 & 16,7 & 17,0 & 16,8 & 16,8 & 16,7 & 16,3 & 16,5 & 16,5 \\
\hline $11 \%$ & 11,1 & 11,3 & 11,2 & 10,9 & 10,6 & 10,6 & 10,7 & 10,5 & 10,8 & 10,6 \\
\hline $7 \%$ & 7,4 & 7,3 & 7,0 & 7,2 & 7,1 & 7,4 & 7,3 & 7,5 & 7,3 & 7,0 \\
\hline
\end{tabular}


Tabela 6. Germinação das sementes de maracujá-amarelo: valores médios ${ }^{1}$ (\%) obtidos durante o armazenamento

\begin{tabular}{|c|c|c|c|c|c|c|c|c|c|c|}
\hline \multirow{2}{*}{$\begin{array}{l}\text { Tratamentos } \\
\text { (temperatura/ } \\
\text { teor de água) }\end{array}$} & \multicolumn{10}{|c|}{ Período de armazenamento (dias) } \\
\hline & 35 & 70 & 105 & 140 & 175 & 210 & 245 & 280 & 315 & 350 \\
\hline $10^{\circ} \mathrm{C} / 31 \%$ & $96 \mathrm{a}$ & $78 \mathrm{c}$ & 73 de & $17 \mathrm{i}$ & $06 \mathrm{f}$ & 17 ef & $00 \mathrm{~h}$ & $00 \mathrm{f}$ & $00 \mathrm{~g}$ & $00 \mathrm{~h}$ \\
\hline $27 \%$ & $94 \mathrm{a}$ & 86 bc & 81 bcd & $56 \mathrm{gh}$ & $67 \mathrm{e}$ & $78 \mathrm{c}$ & 69 ef & $60 \mathrm{~d}$ & $34 \mathrm{f}$ & $00 \mathrm{~h}$ \\
\hline $21 \%$ & 93 a & $90 \mathrm{abc}$ & $94 \mathrm{ab}$ & 78 defg & 65 e & $85 \mathrm{bc}$ & 81 def & $59 \mathrm{~d}$ & $67 \mathrm{e}$ & 51 ef \\
\hline $17 \%$ & $93 \mathrm{a}$ & $92 \mathrm{abc}$ & 99 a & 93 abcd & $97 \mathrm{ab}$ & $97 \mathrm{a}$ & 86 cdef & $94 \mathrm{bc}$ & $97 \mathrm{bc}$ & 95 bc \\
\hline $11 \%$ & $92 \mathrm{a}$ & $96 \mathrm{ab}$ & $95 \mathrm{ab}$ & $96 \mathrm{ab}$ & $92 \mathrm{abc}$ & $95 \mathrm{a}$ & 100 a & $100 \mathrm{a}$ & $90 \mathrm{~cd}$ & $97 \mathrm{abc}$ \\
\hline $7 \%$ & $94 \mathrm{a}$ & $95 \mathrm{ab}$ & $96 \mathrm{a}$ & $95 \mathrm{abc}$ & $92 \mathrm{abc}$ & $94 \mathrm{ab}$ & $99 a b$ & $99 a b$ & $100 \mathrm{a}$ & $99 \mathrm{ab}$ \\
\hline $15^{\circ} \mathrm{C} / 31 \%$ & $95 \mathrm{a}$ & $93 \mathrm{abc}$ & 58 e & $42 \mathrm{~h}$ & $05 \mathrm{f}$ & $12 \mathrm{f}$ & $00 \mathrm{~h}$ & $00 \mathrm{f}$ & $00 \mathrm{~g}$ & $00 \mathrm{~h}$ \\
\hline $27 \%$ & $97 \mathrm{a}$ & $97 \mathrm{ab}$ & $93 \mathrm{ab}$ & 80 cdef & 76 cde & $53 \mathrm{~d}$ & $10 \mathrm{~g}$ & $06 \mathrm{e}$ & $00 \mathrm{~g}$ & $00 \mathrm{~h}$ \\
\hline $21 \%$ & $95 \mathrm{a}$ & $98 \mathrm{ab}$ & $96 \mathrm{a}$ & 87 bcde & 75 de & $75 \mathrm{c}$ & $68 \mathrm{f}$ & $48 \mathrm{~d}$ & $37 \mathrm{f}$ & $30 \mathrm{~g}$ \\
\hline $17 \%$ & $94 \mathrm{a}$ & 99 a & 99 a & $97 \mathrm{ab}$ & $96 \mathrm{ab}$ & $100 \mathrm{a}$ & 95 abcd & 94 bc & 97 bc & 94 bc \\
\hline $11 \%$ & $98 \mathrm{a}$ & $96 \mathrm{ab}$ & $96 \mathrm{a}$ & $96 \mathrm{ab}$ & $94 \mathrm{ab}$ & $96 \mathrm{a}$ & 98 abc & $96 \mathrm{abc}$ & 96 bcd & $90 \mathrm{~cd}$ \\
\hline $7 \%$ & $96 \mathrm{a}$ & $93 \mathrm{abc}$ & $97 \mathrm{a}$ & $95 \mathrm{abc}$ & $94 \mathrm{ab}$ & $96 \mathrm{a}$ & 95 abcd & $96 \mathrm{abc}$ & $88 \mathrm{~d}$ & $80 \mathrm{~d}$ \\
\hline $20^{\circ} \mathrm{C} / 31 \%$ & $92 \mathrm{a}$ & 89 abc & 77 cde & $18 \mathrm{i}$ & $12 \mathrm{f}$ & $27 \mathrm{e}$ & $21 \mathrm{~g}$ & $00 \mathrm{f}$ & $00 \mathrm{~g}$ & $00 \mathrm{~h}$ \\
\hline $27 \%$ & $95 \mathrm{a}$ & $93 \mathrm{abc}$ & $92 \mathrm{abc}$ & 69 efg & 86 bcd & $97 \mathrm{a}$ & 88 cde & $90 \mathrm{c}$ & $58 \mathrm{e}$ & $31 \mathrm{fg}$ \\
\hline $21 \%$ & $94 \mathrm{a}$ & $97 \mathrm{ab}$ & $94 \mathrm{ab}$ & $62 \mathrm{fgh}$ & $97 \mathrm{ab}$ & $96 \mathrm{a}$ & $90 \mathrm{bcd}$ & $93 \mathrm{bc}$ & 63 e & 55 e \\
\hline $17 \%$ & $93 \mathrm{a}$ & 99 a & 97 a & 92 abcd & 98 a & 99 a & $100 \mathrm{a}$ & $99 \mathrm{ab}$ & 95 bcd & $98 \mathrm{ab}$ \\
\hline $11 \%$ & 89 a & $91 \mathrm{abc}$ & $96 \mathrm{a}$ & 95 abc & 89 abcd & $99 \mathrm{a}$ & $100 \mathrm{a}$ & $100 \mathrm{a}$ & 97 bc & $98 \mathrm{ab}$ \\
\hline $7 \%$ & $96 \mathrm{a}$ & $95 \mathrm{ab}$ & $95 \mathrm{ab}$ & 99 a & 90 abcd & $97 \mathrm{a}$ & 98 abc & $99 \mathrm{ab}$ & $99 \mathrm{ab}$ & $100 \mathrm{a}$ \\
\hline
\end{tabular}

1. Médias seguidas pela mesma letra, na coluna, não diferem entre si pelo teste de Tukey a 5\% de probabilidade. 
Tabela 7. Primeira contagem de germinação das sementes de maracujá-amarelo: valores médios ${ }^{1}(\%)$ obtidos durante o armazenamento

\begin{tabular}{|c|c|c|c|c|c|c|c|c|c|c|c|}
\hline \multirow{2}{*}{\multicolumn{2}{|c|}{$\begin{array}{l}\text { Tratamentos } \\
\text { (temperatura/ } \\
\text { teor de água) }\end{array}$}} & \multicolumn{10}{|c|}{ Período de armazenamento (dias) } \\
\hline & & 35 & 70 & 105 & 140 & 175 & 210 & 245 & 280 & 315 & 350 \\
\hline \multirow[t]{6}{*}{$10^{\circ} \mathrm{C} /$} & $31 \%$ & 38 de & $19 \mathrm{~g}$ & 21 gh & $00 \mathrm{~h}$ & $00 \mathrm{~h}$ & $00 \mathrm{~g}$ & $00 \mathrm{~h}$ & $00 \mathrm{~g}$ & $00 \mathrm{~g}$ & $00 \mathrm{~g}$ \\
\hline & $27 \%$ & 40 de & $38 \mathrm{fg}$ & 48 ef & $10 \mathrm{~g}$ & $08 \mathrm{~g}$ & $08 \mathrm{f}$ & $05 \mathrm{fg}$ & $08 \mathrm{f}$ & $05 \mathrm{f}$ & $00 \mathrm{~g}$ \\
\hline & $21 \%$ & 46 bcde & 58 def & 71 abcd & 41 de & 45 ef & $57 \mathrm{~d}$ & $37 \mathrm{~cd}$ & 41 de & 13 ef & $15 \mathrm{f}$ \\
\hline & $17 \%$ & 64 abc & 66 cde & 80 abc & $57 \mathrm{~cd}$ & 88 a & 76 bc & $53 \mathrm{c}$ & 69 c & 84 bc & $92 \mathrm{abc}$ \\
\hline & $11 \%$ & 70 a & 75 abcd & $84 \mathrm{abc}$ & $71 \mathrm{bc}$ & $81 \mathrm{ab}$ & $92 \mathrm{a}$ & $97 \mathrm{a}$ & $95 \mathrm{ab}$ & $84 \mathrm{bc}$ & 90 bcd \\
\hline & $7 \%$ & $71 \mathrm{a}$ & 83 abc & 86 a & $81 \mathrm{ab}$ & 87 a & $88 \mathrm{ab}$ & 98 a & $97 \mathrm{a}$ & $95 \mathrm{a}$ & $97 \mathrm{abc}$ \\
\hline \multirow[t]{6}{*}{$15^{\circ} \mathrm{C} /$} & $31 \%$ & $31 \mathrm{e}$ & 52 ef & $03 \mathrm{i}$ & $00 \mathrm{~h}$ & $00 \mathrm{~h}$ & $00 \mathrm{~g}$ & $00 \mathrm{~h}$ & $00 \mathrm{~g}$ & $00 \mathrm{~g}$ & $00 \mathrm{~g}$ \\
\hline & $27 \%$ & 42 cde & 66 cde & 38 fg & $21 \mathrm{ef}$ & $16 \mathrm{~g}$ & $11 \mathrm{f}$ & $00 \mathrm{~h}$ & $01 \mathrm{fg}$ & $00 \mathrm{~g}$ & $00 \mathrm{~g}$ \\
\hline & $21 \%$ & 49 abcde & 79 abcd & 66 cde & $54 \mathrm{~cd}$ & $50 \mathrm{de}$ & $31 \mathrm{e}$ & 15 ef & $34 \mathrm{e}$ & 10 ef & $00 \mathrm{~g}$ \\
\hline & $17 \%$ & 64 abc & $86 \mathrm{ab}$ & 72 abcd & $83 \mathrm{ab}$ & $84 \mathrm{a}$ & $51 \mathrm{~d}$ & 27 de & $67 c$ & 79 bc & $87 \mathrm{~cd}$ \\
\hline & $11 \%$ & $66 \mathrm{ab}$ & $88 \mathrm{a}$ & 82 abc & $89 \mathrm{ab}$ & $85 \mathrm{a}$ & 75 bc & 83 b & $87 \mathrm{~b}$ & $87 \mathrm{ab}$ & 75 de \\
\hline & $7 \%$ & $72 \mathrm{a}$ & 89 a & 85 ab & $90 \mathrm{ab}$ & 80 abc & 75 bc & $93 \mathrm{ab}$ & $87 \mathrm{~b}$ & 81 bc & $65 \mathrm{e}$ \\
\hline \multirow[t]{6}{*}{$20^{\circ} \mathrm{C} /$} & $31 \%$ & 61 abcd & 67 bcde & $14 \mathrm{hi}$ & $00 \mathrm{~h}$ & $00 \mathrm{~h}$ & $00 \mathrm{~g}$ & $00 \mathrm{~h}$ & $00 \mathrm{~g}$ & $00 \mathrm{~g}$ & $00 \mathrm{~g}$ \\
\hline & $27 \%$ & $70 \mathrm{a}$ & 74 abcde & $36 \mathrm{fg}$ & $13 \mathrm{~g}$ & $31 \mathrm{f}$ & $32 \mathrm{e}$ & 03 gh & $27 \mathrm{e}$ & $18 \mathrm{e}$ & $00 \mathrm{~g}$ \\
\hline & $21 \%$ & $72 \mathrm{a}$ & 80 abc & 53 def & 38 ef & 44 ef & $62 \mathrm{~cd}$ & $53 \mathrm{c}$ & $58 \mathrm{~cd}$ & $46 \mathrm{~d}$ & $21 \mathrm{f}$ \\
\hline & $17 \%$ & 60 abcd & 90 a & 67 bcde & $85 \mathrm{ab}$ & $86 \mathrm{a}$ & $91 \mathrm{a}$ & $98 \mathrm{a}$ & $96 \mathrm{ab}$ & $73 \mathrm{c}$ & $97 \mathrm{abc}$ \\
\hline & $11 \%$ & $68 \mathrm{ab}$ & $86 \mathrm{ab}$ & 70 abcd & $82 \mathrm{ab}$ & $65 \mathrm{~cd}$ & $92 \mathrm{a}$ & $91 \mathrm{ab}$ & $92 \mathrm{ab}$ & $95 \mathrm{a}$ & $98 \mathrm{ab}$ \\
\hline & $7 \%$ & $64 \mathrm{abc}$ & 76 abcd & 78 abc & $92 \mathrm{a}$ & 67 bcd & $83 a b$ & $90 \mathrm{ab}$ & $92 \mathrm{ab}$ & $87 \mathrm{ab}$ & 99 a \\
\hline
\end{tabular}

1. Médias seguidas pela mesma letra, na coluna, não diferem entre si pelo teste de Tukey a 5\% de probabilidade. 
Tabela 8. Comprimento de raiz em maracujá-amarelo: valores médios ${ }^{1}(\mathrm{~mm})$ obtidos durante o armazenamento

\begin{tabular}{|c|c|c|c|c|c|c|c|c|c|c|c|}
\hline \multirow{2}{*}{\multicolumn{2}{|c|}{$\begin{array}{l}\text { Tratamentos } \\
\text { (temperatura/ } \\
\text { teor de água) }\end{array}$}} & \multicolumn{10}{|c|}{ Período de armazenamento (dias) } \\
\hline & & 35 & 70 & 105 & 140 & 175 & 210 & 245 & 280 & 315 & 350 \\
\hline \multirow[t]{6}{*}{$10^{\circ} \mathrm{C} /$} & $31 \%$ & 84 abcde & 63 de & $77 \mathrm{abc}$ & 48 def & 13 de & 11 de & $00 \mathrm{~g}$ & $00 \mathrm{~g}$ & $00 \mathrm{f}$ & $00 \mathrm{f}$ \\
\hline & $27 \%$ & $90 \mathrm{ab}$ & 73 bcde & $84 \mathrm{ab}$ & 70 bcd & $45 \mathrm{~cd}$ & $37 \mathrm{~cd}$ & $34 \mathrm{f}$ & $52 \mathrm{e}$ & 13 ef & $00 \mathrm{f}$ \\
\hline & $21 \%$ & 95 a & 79 abcd & $88 \mathrm{ab}$ & $79 \mathrm{abc}$ & $65 \mathrm{abc}$ & $62 \mathrm{bc}$ & 52 def & 62 de & 21 e & $24 \mathrm{e}$ \\
\hline & $17 \%$ & $89 \mathrm{abc}$ & 87 abc & $89 \mathrm{ab}$ & $91 \mathrm{ab}$ & $86 \mathrm{ab}$ & $97 \mathrm{a}$ & $88 \mathrm{ab}$ & $91 \mathrm{abc}$ & $85 \mathrm{abc}$ & 46 de \\
\hline & $11 \%$ & 93 a & $92 \mathrm{ab}$ & $92 \mathrm{a}$ & $98 \mathrm{a}$ & 78 abc & 61 bc & 102 a & $102 a b$ & $90 \mathrm{ab}$ & $63 \mathrm{~cd}$ \\
\hline & $7 \%$ & 88 abcd & $95 \mathrm{a}$ & $91 \mathrm{a}$ & $96 \mathrm{a}$ & 93 a & $80 a b$ & $94 \mathrm{ab}$ & 108 a & 98 a & $96 \mathrm{a}$ \\
\hline \multirow[t]{6}{*}{$15^{\circ} \mathrm{C} /$} & $31 \%$ & $62 \mathrm{fg}$ & 70 cde & $58 \mathrm{c}$ & $27 \mathrm{f}$ & $03 \mathrm{e}$ & 07 e & $00 \mathrm{~g}$ & $00 \mathrm{~g}$ & $00 \mathrm{f}$ & $00 \mathrm{f}$ \\
\hline & $27 \%$ & 71 cdef & 75 abcde & 70 bc & 50 def & $68 \mathrm{abc}$ & $50 \mathrm{c}$ & $03 \mathrm{~g}$ & $08 \mathrm{~g}$ & $00 \mathrm{f}$ & $00 \mathrm{f}$ \\
\hline & $21 \%$ & 81 abcde & 74 bcde & 71 bc & 70 bcd & 73 abc & $77 \mathrm{ab}$ & 40 ef & $28 \mathrm{f}$ & $20 \mathrm{e}$ & $28 \mathrm{e}$ \\
\hline & $17 \%$ & 78 abcdef & 80 abcd & 92 a & $78 \mathrm{abc}$ & $83 \mathrm{ab}$ & $94 \mathrm{a}$ & $83 \mathrm{ab}$ & 79 cd & 75 c & $95 \mathrm{a}$ \\
\hline & $11 \%$ & 73 bcdef & 84 abc & $85 \mathrm{ab}$ & $82 \mathrm{abc}$ & 93 a & $92 \mathrm{a}$ & $71 \mathrm{bcd}$ & $90 \mathrm{abc}$ & 85 abc & $88 \mathrm{ab}$ \\
\hline & $7 \%$ & 83 abcde & $92 \mathrm{ab}$ & $87 \mathrm{ab}$ & $92 \mathrm{ab}$ & $93 \mathrm{a}$ & 89 a & 58 cde & $80 \mathrm{~cd}$ & $74 \mathrm{c}$ & 95 a \\
\hline \multirow[t]{6}{*}{$20^{\circ} \mathrm{C} /$} & $31 \%$ & $40 \mathrm{~h}$ & $57 \mathrm{e}$ & 58 c & 42 ef & 16 de & $21 \mathrm{de}$ & $00 \mathrm{~g}$ & $00 \mathrm{~g}$ & $00 \mathrm{f}$ & $00 \mathrm{f}$ \\
\hline & $27 \%$ & $60 \mathrm{fg}$ & 75 abcde & $78 \mathrm{ab}$ & 63 cde & 76 abc & $82 \mathrm{ab}$ & 59 cde & 86 bc & $50 \mathrm{~d}$ & 38 e \\
\hline & $21 \%$ & $50 \mathrm{gh}$ & 78 abcd & $79 \mathrm{ab}$ & $79 \mathrm{abc}$ & 55 bc & $90 \mathrm{a}$ & 59 cde & $93 \mathrm{abc}$ & $74 \mathrm{c}$ & 44 de \\
\hline & $17 \%$ & $48 \mathrm{gh}$ & $87 \mathrm{abc}$ & $88 \mathrm{ab}$ & 85 abc & 63 abc & $92 \mathrm{a}$ & $84 \mathrm{ab}$ & $100 \mathrm{ab}$ & $58 d$ & 82 abc \\
\hline & $11 \%$ & $66 \mathrm{efg}$ & $84 \mathrm{abc}$ & $82 \mathrm{ab}$ & $81 \mathrm{abc}$ & $63 \mathrm{abc}$ & $90 \mathrm{a}$ & $81 \mathrm{abc}$ & 108 a & 81 bc & 72 bc \\
\hline & $7 \%$ & 70 def & $91 \mathrm{ab}$ & $82 \mathrm{ab}$ & 85 abc & $63 \mathrm{abc}$ & $96 \mathrm{a}$ & 99 a & $95 \mathrm{abc}$ & 81 bc & $88 \mathrm{ab}$ \\
\hline
\end{tabular}

1. Médias seguidas pela mesma letra, na coluna, não diferem entre si pelo teste de Tukey a 5\% de probabilidade. 
Tabela 9. Comprimento de hipocótilo em maracujá-amarelo: valores médios ${ }^{1}(\mathrm{~mm})$ obtidos durante o armazenamento

\begin{tabular}{|c|c|c|c|c|c|c|c|c|c|c|c|}
\hline \multirow{2}{*}{\multicolumn{2}{|c|}{$\begin{array}{l}\text { Tratamentos } \\
\text { (temperatura/ } \\
\text { teor de água) }\end{array}$}} & \multicolumn{10}{|c|}{ Período de armazenamento (dias) } \\
\hline & & 35 & 70 & 105 & 140 & 175 & 210 & 245 & 280 & 315 & 350 \\
\hline \multirow[t]{6}{*}{$10^{\circ} \mathrm{C} /$} & $31 \%$ & 65 bcd & $44 \mathrm{e}$ & 52 cde & $24 \mathrm{hi}$ & $09 \mathrm{fg}$ & $09 \mathrm{~g}$ & $00 \mathrm{~h}$ & $00 \mathrm{f}$ & 00 e & $00 \mathrm{~g}$ \\
\hline & $27 \%$ & 62 cde & 55 de & 51 cde & 46 efgh & 28 ef & 37 ef & $27 \mathrm{fg}$ & 28 de & 09 e & $00 \mathrm{~g}$ \\
\hline & $21 \%$ & 67 abcd & 58 cde & 61 abcd & 58 defg & 49 de & 73 bcd & 40 defg & $37 \mathrm{~d}$ & 10 e & 15 efg \\
\hline & $17 \%$ & $80 \mathrm{a}$ & 62 bcde & 66 abcd & 70 cde & $84 \mathrm{ab}$ & $93 \mathrm{ab}$ & $69 \mathrm{~b}$ & $84 \mathrm{~b}$ & $63 \mathrm{c}$ & $43 \mathrm{~cd}$ \\
\hline & $11 \%$ & $79 a b$ & 74 abcd & 77 abc & 85 abcd & $84 \mathrm{ab}$ & $61 \mathrm{~d}$ & 95 a & $106 \mathrm{a}$ & $77 \mathrm{ab}$ & 61 bc \\
\hline & $7 \%$ & 80 a & 76 abcd & $83 \mathrm{ab}$ & 84 abcd & $91 \mathrm{a}$ & 97 a & 93 a & $107 \mathrm{a}$ & $84 \mathrm{a}$ & $84 \mathrm{a}$ \\
\hline \multirow[t]{6}{*}{$15^{\circ} \mathrm{C} /$} & $31 \%$ & 53 def & 63 bcde & 26 e & $08 \mathrm{i}$ & $02 \mathrm{~g}$ & $05 \mathrm{~g}$ & $00 \mathrm{~h}$ & $00 \mathrm{f}$ & 00 e & $00 \mathrm{~g}$ \\
\hline & $27 \%$ & 56 cde & 60 bcde & 43 de & 19 hi & $52 \mathrm{de}$ & $32 \mathrm{f}$ & $02 \mathrm{~h}$ & $07 \mathrm{f}$ & 00 e & $00 \mathrm{~g}$ \\
\hline & $21 \%$ & 58 cde & 69 bcd & $58 \mathrm{bcd}$ & 39 fgh & $65 \mathrm{bcd}$ & 58 de & 21 gh & 15 ef & $10 \mathrm{e}$ & $13 \mathrm{fg}$ \\
\hline & $17 \%$ & $68 \mathrm{abc}$ & 72 abcd & $72 \mathrm{abc}$ & 61 defg & 79 abc & 74 bcd & 54 bcde & 65 bc & $60 \mathrm{c}$ & $83 \mathrm{a}$ \\
\hline & $11 \%$ & 67 abcd & 79 abc & 74 abc & 82 bcd & $88 \mathrm{ab}$ & 86 abc & 62 bcd & 66 bc & $72 \mathrm{abc}$ & $79 a b$ \\
\hline & $7 \%$ & 68 abc & $82 \mathrm{ab}$ & 86 a & $106 \mathrm{ab}$ & $88 \mathrm{ab}$ & 82 abc & 34 efg & 65 bc & 79 a & $86 \mathrm{a}$ \\
\hline \multirow[t]{6}{*}{$20^{\circ} \mathrm{C} /$} & $31 \%$ & $40 \mathrm{fgh}$ & 75 abcd & $43 \mathrm{de}$ & 32 ghi & $14 \mathrm{fg}$ & $18 \mathrm{fg}$ & $00 \mathrm{~h}$ & $00 \mathrm{f}$ & 00 e & $00 \mathrm{~g}$ \\
\hline & $27 \%$ & $32 \mathrm{~h}$ & 61 bcde & 42 de & 62 def & 68 abcd & 70 cd & $28 \mathrm{fg}$ & $58 \mathrm{c}$ & $31 \mathrm{~d}$ & 25 def \\
\hline & $21 \%$ & $39 \mathrm{gh}$ & 66 bcde & 50 cde & 66 cdef & 48 de & 72 bcd & 45 cdef & 59 c & $43 \mathrm{~d}$ & 34 de \\
\hline & $17 \%$ & 48 efg & 73 abcd & 66 abcd & 94 abc & $63 \mathrm{bcd}$ & 76 abcd & 68 bc & $80 \mathrm{~b}$ & 66 bc & $84 \mathrm{a}$ \\
\hline & $11 \%$ & 49 efg & $82 \mathrm{ab}$ & 67 abcd & 85 abcd & $55 \mathrm{~cd}$ & 75 abcd & 67 bc & 82 b & $61 \mathrm{c}$ & 85 a \\
\hline & $7 \%$ & 62 cde & 93 a & 68 abcd & $112 \mathrm{a}$ & $64 \mathrm{bcd}$ & 77 abcd & $73 \mathrm{ab}$ & 77 bc & $78 \mathrm{ab}$ & $86 \mathrm{a}$ \\
\hline
\end{tabular}

1. Médias seguidas pela mesma letra, na coluna, não diferem entre si pelo teste de Tukey a 5\% de probabilidade. 
Tabela 10. Comprimento de plântula em maracujá-amarelo: valores médios ${ }^{1}(\mathrm{~mm})$ obtidos durante o armazenamento

\begin{tabular}{|c|c|c|c|c|c|c|c|c|c|c|c|}
\hline \multirow{2}{*}{\multicolumn{2}{|c|}{$\begin{array}{l}\text { Tratamentos } \\
\text { (temperatura/ } \\
\text { teor de água) }\end{array}$}} & \multicolumn{10}{|c|}{ Período de armazenamento (dias) } \\
\hline & & 35 & 70 & 105 & 140 & 175 & 210 & 245 & 280 & 315 & 350 \\
\hline \multirow[t]{6}{*}{$10^{\circ} \mathrm{C} /$} & $31 \%$ & 149 abc & $107 \mathrm{e}$ & 128 cdef & 72 hi & $22 \mathrm{fg}$ & $20 \mathrm{~g}$ & $00 \mathrm{~h}$ & $00 \mathrm{~h}$ & $00 \mathrm{i}$ & $00 \mathrm{f}$ \\
\hline & $27 \%$ & $152 \mathrm{abc}$ & 128 de & 135abcdef & 116 efgh & 72 ef & 74 ef & $61 \mathrm{~g}$ & 78 ef & $22 \mathrm{hi}$ & $00 \mathrm{f}$ \\
\hline & $21 \%$ & $162 \mathrm{ab}$ & 136 bcde & 150 abcde & 137 cdef & 117 cde & 135 bc & $92 \mathrm{fg}$ & 99 e & $31 \mathrm{~h}$ & 39 ef \\
\hline & $17 \%$ & 169 a & 152 abcd & 155 abcde & 161abcdef & $170 \mathrm{abc}$ & $190 \mathrm{a}$ & 158 bcd & 175 bcd & 147 bcd & $90 \mathrm{~cd}$ \\
\hline & $11 \%$ & $172 \mathrm{a}$ & 165 abcd & 169 abc & 184 abc & $162 \mathrm{abc}$ & $122 \mathrm{~cd}$ & 197 a & $209 \mathrm{ab}$ & $166 \mathrm{ab}$ & 124 bc \\
\hline & $7 \%$ & 168 a & $171 \mathrm{abc}$ & $174 \mathrm{a}$ & 180 abc & $184 \mathrm{a}$ & 178 a & $187 \mathrm{ab}$ & 215 a & 182 a & $180 \mathrm{a}$ \\
\hline \multirow[t]{6}{*}{$15^{\circ} \mathrm{C} /$} & $31 \%$ & 115 cdef & 134 bcde & $84 \mathrm{~g}$ & $35 \mathrm{i}$ & $05 \mathrm{~g}$ & $12 \mathrm{~g}$ & $00 \mathrm{~h}$ & $00 \mathrm{~h}$ & $00 \mathrm{i}$ & $00 \mathrm{f}$ \\
\hline & $27 \%$ & 127 bcde & 135 bcde & 113 efg & $69 \mathrm{hi}$ & 120 cde & 82 de & $05 \mathrm{~h}$ & $14 \mathrm{gh}$ & $00 \mathrm{i}$ & $00 \mathrm{f}$ \\
\hline & $21 \%$ & 139 abc & 143 abcde & 130 bcdef & 109 fgh & 138 abcd & 136 bc & $61 \mathrm{~g}$ & $43 \mathrm{fg}$ & $30 \mathrm{~h}$ & 41 ef \\
\hline & $17 \%$ & $147 \mathrm{abc}$ & 153 abcd & 165 abc & 139 cdef & 162 abc & $168 \mathrm{ab}$ & 137 cde & $144 \mathrm{~d}$ & 134 def & $178 \mathrm{a}$ \\
\hline & $11 \%$ & 140 abc & 164 abcd & 159 abcd & 165 abcde & $181 \mathrm{ab}$ & 178 a & 133 de & $157 \mathrm{~cd}$ & 158 bc & $168 \mathrm{a}$ \\
\hline & $7 \%$ & 151 abc & $175 \mathrm{ab}$ & $173 \mathrm{ab}$ & 198 a & 182 a & $172 \mathrm{ab}$ & $92 \mathrm{fg}$ & $145 d$ & 152 bcd & $181 \mathrm{a}$ \\
\hline \multirow[t]{6}{*}{$20^{\circ} \mathrm{C} /$} & $31 \%$ & $80 \mathrm{f}$ & 132 cde & $101 \mathrm{fg}$ & 74 ghi & $31 \mathrm{fg}$ & $36 \mathrm{fg}$ & $00 \mathrm{~h}$ & $00 \mathrm{~h}$ & $00 \mathrm{i}$ & $00 \mathrm{f}$ \\
\hline & $27 \%$ & 92 def & 137 bcde & 120 defg & 126 defg & 144 abcd & 153 abc & $87 \mathrm{fg}$ & $144 \mathrm{~d}$ & $81 \mathrm{~g}$ & 63 de \\
\hline & $21 \%$ & 90 ef & 144abcde & 130 bcdef & 145 bcdef & 103 de & $162 \mathrm{abc}$ & 104 ef & 152 cd & $117 \mathrm{f}$ & 78 de \\
\hline & $17 \%$ & 96 def & 160 abcd & 154 abcde & 178 abcd & 126 cd & $168 \mathrm{ab}$ & $153 \mathrm{bcd}$ & 180 abcd & 123 ef & $166 \mathrm{a}$ \\
\hline & $11 \%$ & 114 cdef & 166 abcd & 149 abcde & 166 abcde & 119 cde & $166 \mathrm{ab}$ & $148 \mathrm{~cd}$ & $190 \mathrm{abc}$ & 142 cde & $157 \mathrm{ab}$ \\
\hline & $7 \%$ & $132 \mathrm{abcd}$ & $184 \mathrm{a}$ & 149 abcde & $197 \mathrm{ab}$ & $128 \mathrm{bcd}$ & $174 \mathrm{ab}$ & 172 abc & 172 bcd & 159 bc & $175 \mathrm{a}$ \\
\hline
\end{tabular}

1. Médias seguidas pela mesma letra, na coluna, não diferem entre si pelo teste de Tukey a 5\% de probabilidade. 
Tabela 11. Emergência de plântula em maracujá-amarelo: valores médios ${ }^{1}$ (\%) obtidos durante o armazenamento

\begin{tabular}{|c|c|c|c|c|c|c|c|c|c|c|c|}
\hline \multirow{2}{*}{\multicolumn{2}{|c|}{$\begin{array}{l}\text { Tratamentos } \\
\text { (temperatura/ } \\
\text { teor de água) }\end{array}$}} & \multicolumn{10}{|c|}{ Período de armazenamento (dias) } \\
\hline & & 35 & 70 & 105 & 140 & 175 & 210 & 245 & 280 & 315 & 350 \\
\hline \multirow[t]{6}{*}{$10^{\circ} \mathrm{C} /$} & $31 \%$ & $08 \mathrm{f}$ & $03 \mathrm{i}$ & $03 \mathrm{~g}$ & $06 \mathrm{gh}$ & $00 \mathrm{f}$ & $00 \mathrm{~d}$ & $00 \mathrm{f}$ & $00 \mathrm{f}$ & $00 \mathrm{~d}$ & $00 \mathrm{f}$ \\
\hline & $27 \%$ & 10 ef & 06 fghi & $10 \mathrm{fg}$ & $11 \mathrm{fg}$ & 02 ef & 03 bcd & $00 \mathrm{f}$ & $00 \mathrm{f}$ & $00 \mathrm{~d}$ & $00 \mathrm{f}$ \\
\hline & $21 \%$ & 12 def & 09 efghi & 13 efg & $17 \mathrm{efg}$ & 11 de & 11 bc & 03 ef & 10 de & $00 \mathrm{~d}$ & 05 def \\
\hline & $17 \%$ & 20 abcdef & 15 defghi & 20 def & 33 cde & $22 \mathrm{~cd}$ & $15 \mathrm{~b}$ & 11 de & $14 \mathrm{~d}$ & $06 \mathrm{c}$ & 08 de \\
\hline & $11 \%$ & 26 abc & 21 bcdefg & 33 bcd & 39 bcde & 40 bc & $54 \mathrm{a}$ & $54 \mathrm{ab}$ & 48 bc & 17 bc & $32 \mathrm{abc}$ \\
\hline & $7 \%$ & 24 abcd & 27 abcde & 31 cde & 50 abcd & $51 \mathrm{ab}$ & $59 \mathrm{a}$ & $69 a b$ & 79 a & $48 \mathrm{a}$ & $39 a b$ \\
\hline \multirow[t]{6}{*}{$15^{\circ} \mathrm{C} /$} & $31 \%$ & 09 ef & $04 \mathrm{hi}$ & $01 \mathrm{~g}$ & $00 \mathrm{~h}$ & $00 \mathrm{f}$ & $00 \mathrm{~d}$ & $00 \mathrm{f}$ & $00 \mathrm{f}$ & $00 \mathrm{~d}$ & $00 \mathrm{f}$ \\
\hline & $27 \%$ & 12 def & 18cdefghi & 21 def & $00 \mathrm{~h}$ & 04 ef & $00 \mathrm{~d}$ & 03 ef & $00 \mathrm{f}$ & $00 \mathrm{~d}$ & $00 \mathrm{f}$ \\
\hline & $21 \%$ & 15 bcdef & 23 bcdef & 27 cdef & 18 efg & 12 de & 09 bc & 06 ef & 08 de & $00 \mathrm{~d}$ & 01 ef \\
\hline & $17 \%$ & 19 bcdef & 20 cdefgh & 35 abcd & 31 cdef & 08 de & 13 bc & 07 def & $18 \mathrm{~d}$ & $05 \mathrm{~cd}$ & $15 \mathrm{~cd}$ \\
\hline & $11 \%$ & 21 abcde & 35 abcd & 41 abcd & 54 abc & 44 abc & $67 \mathrm{a}$ & $56 \mathrm{ab}$ & $50 \mathrm{~b}$ & $40 \mathrm{a}$ & $51 \mathrm{a}$ \\
\hline & $7 \%$ & 25 abcd & 38 abcd & 47 abc & $71 \mathrm{a}$ & $66 \mathrm{a}$ & $64 \mathrm{a}$ & 73 a & $77 \mathrm{a}$ & $46 \mathrm{a}$ & $43 \mathrm{a}$ \\
\hline \multirow[t]{6}{*}{$20^{\circ} \mathrm{C} /$} & $31 \%$ & 13 cdef & 20 cdefgh & $03 \mathrm{~g}$ & $00 \mathrm{~h}$ & $00 \mathrm{f}$ & $00 \mathrm{~d}$ & $00 \mathrm{f}$ & $00 \mathrm{f}$ & $00 \mathrm{~d}$ & $00 \mathrm{f}$ \\
\hline & $27 \%$ & 17 bcdef & 36 abcd & 20 def & 04 gh & $01 \mathrm{ef}$ & $01 \mathrm{~cd}$ & $00 \mathrm{f}$ & $01 \mathrm{ef}$ & $00 \mathrm{~d}$ & $00 \mathrm{f}$ \\
\hline & $21 \%$ & 20 abcdef & 40 abc & 27 cdef & 28 def & 05 ef & 05 bcd & $26 \mathrm{~cd}$ & $25 \mathrm{~cd}$ & 18 bc & 11 de \\
\hline & $17 \%$ & 25 abcd & $42 \mathrm{abc}$ & 46 abc & 65 a & 08 de & 11 bc & 45 bc & 45 bc & $32 \mathrm{ab}$ & $20 \mathrm{bcc}$ \\
\hline & $11 \%$ & $29 \mathrm{ab}$ & $46 \mathrm{ab}$ & $54 \mathrm{ab}$ & $62 \mathrm{ab}$ & $58 \mathrm{ab}$ & $64 \mathrm{a}$ & 75 a & $61 \mathrm{ab}$ & $25 \mathrm{ab}$ & 30 abc \\
\hline & $7 \%$ & 35 a & $52 \mathrm{a}$ & $57 \mathrm{a}$ & $62 \mathrm{ab}$ & $54 \mathrm{ab}$ & $74 \mathrm{a}$ & $79 \mathrm{a}$ & $70 \mathrm{ab}$ & $44 \mathrm{a}$ & $34 \mathrm{abc}$ \\
\hline
\end{tabular}

1. Médias seguidas pela mesma letra, na coluna, não diferem entre si pelo teste de Tukey a 5\% de probabilidade. 
Tabela 12. Índice de velocidade de emergência de plântula (IVE) em maracujá-amarelo: valores médios ${ }^{1}$ obtidos durante o armazenamento

\begin{tabular}{|c|c|c|c|c|c|c|c|c|c|c|c|}
\hline \multirow{2}{*}{\multicolumn{2}{|c|}{$\begin{array}{l}\text { Tratamentos } \\
\text { (temperatura/ } \\
\text { teor de água) }\end{array}$}} & \multicolumn{10}{|c|}{ Período de armazenamento (dias) } \\
\hline & & 35 & 70 & 105 & 140 & 175 & 210 & 245 & 280 & 315 & 350 \\
\hline \multirow[t]{6}{*}{$10^{\circ} \mathrm{C} /$} & $31 \%$ & $0,11 \mathrm{e}$ & $0,04 \mathrm{~g}$ & $0,05 \mathrm{~g}$ & $0,04 \mathrm{c}$ & $00 \mathrm{c}$ & $00 \mathrm{c}$ & $00 \mathrm{~d}$ & $00 \mathrm{f}$ & $00 \mathrm{e}$ & $00 \mathrm{f}$ \\
\hline & $27 \%$ & $0,12 \mathrm{e}$ & $0,06 \mathrm{fg}$ & $0,10 \mathrm{fg}$ & $0,11 \mathrm{c}$ & $0,03 \mathrm{c}$ & $0,03 \mathrm{c}$ & $00 \mathrm{~d}$ & $00 \mathrm{f}$ & 00 e & $00 \mathrm{f}$ \\
\hline & $21 \%$ & 0,16 de & 0,10 efg & 0,14 efg & $0,13 \mathrm{c}$ & $0,16 \mathrm{c}$ & $0,14 \mathrm{c}$ & $0,03 \mathrm{~d}$ & 0,11 ef & 00 e & 0,04 ef \\
\hline & $17 \%$ & 0,27 bcde & 0,18 efg & 0,18 efg & 0,29 bc & $0,27 \mathrm{c}$ & $0,23 \mathrm{c}$ & $0,16 \mathrm{~d}$ & 0,15 ef & 0,07 de & 0,07 ef \\
\hline & $11 \%$ & 0,35 abcd & 0,23 defg & 0,32 cde & $0,51 a b$ & $0,73 \mathrm{~b}$ & $1,07 \mathrm{~b}$ & 0,96 bc & $0,76 \mathrm{~cd}$ & 0,21 cde & $0,34 \mathrm{abc}$ \\
\hline & $7 \%$ & 0,33 abcd & 0,32 bcde & 0,31 cde & 0,59 a & $0,97 \mathrm{ab}$ & 1,33 ab & $1,24 \mathrm{ab}$ & 1,27 a & $0,61 \mathrm{a}$ & $0,41 \mathrm{ab}$ \\
\hline \multirow[t]{6}{*}{$15^{\circ} \mathrm{C} /$} & $31 \%$ & $0,12 \mathrm{e}$ & $0,05 \mathrm{fg}$ & $0,01 \mathrm{~g}$ & $00 \mathrm{c}$ & $00 \mathrm{c}$ & $00 \mathrm{c}$ & $00 \mathrm{~d}$ & $00 \mathrm{f}$ & 00 e & $00 \mathrm{f}$ \\
\hline & $27 \%$ & 0,15 de & 0,24 defg & 0,18 efg & $00 \mathrm{c}$ & 0,07 c & $00 \mathrm{c}$ & $0,03 \mathrm{~d}$ & $00 \mathrm{f}$ & $00 \mathrm{e}$ & $00 \mathrm{f}$ \\
\hline & $21 \%$ & 0,18 cde & 0,31 bcde & 0,25 def & $0,17 \mathrm{c}$ & 0,19 c & $0,15 \mathrm{c}$ & $0,06 \mathrm{~d}$ & 0,08 ef & 00 e & $0,01 \mathrm{f}$ \\
\hline & $17 \%$ & 0,27 bcde & 0,27 cdef & 0,33 bcde & 0,29 bc & $0,13 \mathrm{c}$ & 0,19 с & $0,08 \mathrm{~d}$ & 0,19 ef & 0,05 e & 0,14 def \\
\hline & $11 \%$ & 0,28abcde & $0,52 \mathrm{ab}$ & 0,40 abcd & $0,52 a b$ & $0,85 \mathrm{~b}$ & $1,32 a b$ & $1,01 \mathrm{~b}$ & $0,67 \mathrm{~d}$ & $0,49 \mathrm{ab}$ & 0,49 a \\
\hline & $7 \%$ & 0,33 abcd & 0,63 a & 0,45 abc & 0,78 a & $1,28 \mathrm{a}$ & $1,43 a b$ & 1,35 a & $1,07 \mathrm{ab}$ & $0,47 \mathrm{ab}$ & $0,45 \mathrm{ab}$ \\
\hline \multirow[t]{6}{*}{$20^{\circ} \mathrm{C} /$} & $31 \%$ & 0,17 de & 0,30 bcde & $0,05 \mathrm{~g}$ & $00 \mathrm{c}$ & $00 \mathrm{c}$ & $00 \mathrm{c}$ & $00 \mathrm{~d}$ & $00 \mathrm{f}$ & $00 \mathrm{e}$ & $00 \mathrm{f}$ \\
\hline & $27 \%$ & 0,23 bcde & 0,43 abcd & 0,18 efg & $0,06 \mathrm{c}$ & $0,01 \mathrm{c}$ & 0,02 c & $00 \mathrm{~d}$ & $0,01 \mathrm{f}$ & 00 e & $00 \mathrm{f}$ \\
\hline & $21 \%$ & 0,28abcde & 0,47 abc & 0,25 def & 0,27 bc & $0,08 \mathrm{c}$ & $0,11 \mathrm{c}$ & $0,32 \mathrm{~d}$ & 0,33 e & 0,18 cde & 0,10 ef \\
\hline & $17 \%$ & 0,38 abc & 0,49 abc & 0,42 abcd & $0,50 a b$ & $0,12 \mathrm{c}$ & 0,17 c & $0,66 \mathrm{c}$ & $0,62 \mathrm{~d}$ & $0,37 \mathrm{abc}$ & 0,21 cde \\
\hline & $11 \%$ & $0,42 \mathrm{ab}$ & 0,49 abc & $0,52 \mathrm{ab}$ & 0,64 a & $1,12 \mathrm{ab}$ & $1,33 a b$ & $1,40 \mathrm{a}$ & $1,12 \mathrm{ab}$ & $0,31 \mathrm{bcd}$ & $0,30 \mathrm{bcd}$ \\
\hline & $7 \%$ & $0,48 \mathrm{a}$ & $0,55 \mathrm{a}$ & $0,54 \mathrm{a}$ & $0,66 \mathrm{a}$ & $1,09 \mathrm{ab}$ & $1,61 \mathrm{a}$ & $1,46 \mathrm{a}$ & $0,96 \mathrm{bc}$ & $0,54 \mathrm{ab}$ & 0,35 abc \\
\hline
\end{tabular}

1. Médias seguidas pela mesma letra, na coluna, não diferem entre si pelo teste de Tukey a 5\% de probabilidade. 
Tabela 13. Classificação estatística: pontuações parciais ( $\sum$ das pontuações obtidas nas avaliações fisiológicas por período de armazenamento) e total ( $\sum$ das pontuações parciais) atribuídas aos tratamentos

\begin{tabular}{|c|c|c|c|c|c|c|c|c|c|c|c|c|}
\hline \multirow{2}{*}{\multicolumn{2}{|c|}{$\begin{array}{l}\text { Tratamentos } \\
\text { (temperatura/ } \\
\text { teor de água) }\end{array}$}} & \multicolumn{11}{|c|}{ Período de armazenamento (dias) } \\
\hline & & 35 & 70 & 105 & 140 & 175 & 210 & 245 & 280 & 315 & 350 & Total \\
\hline \multirow[t]{6}{*}{$10^{\circ} \mathrm{C} /$} & $31 \%$ & -11 & -75 & -52 & -83 & -89 & -91 & -86 & -90 & -80 & -76 & -733 \\
\hline & $27 \%$ & -10 & -42 & -28 & -41 & -54 & -60 & -44 & -57 & -63 & -76 & -475 \\
\hline & $21 \%$ & +9 & -23 & +2 & -11 & -21 & -14 & -26 & -36 & -49 & -38 & -207 \\
\hline & $17 \%$ & +27 & -12 & +10 & +13 & +32 & +29 & +19 & +18 & +36 & +12 & +184 \\
\hline & $11 \%$ & +39 & +4 & +28 & +47 & +53 & +35 & +82 & +75 & +50 & +49 & +462 \\
\hline & $7 \%$ & +35 & +17 & +35 & +56 & +67 & +64 & +82 & +90 & +98 & +79 & +623 \\
\hline \multirow[t]{6}{*}{$15^{\circ} \mathrm{C} /$} & $31 \%$ & -38 & -35 & -92 & -88 & -92 & -93 & -86 & -90 & -80 & -76 & -770 \\
\hline & $27 \%$ & -15 & -12 & -25 & -60 & -26 & -66 & -81 & -84 & -80 & -76 & -525 \\
\hline & $21 \%$ & +6 & +5 & +5 & -19 & -5 & -14 & -54 & -51 & -54 & -54 & -235 \\
\hline & $17 \%$ & +14 & +8 & +30 & +21 & +25 & +15 & +11 & +9 & +20 & +50 & +203 \\
\hline & $11 \%$ & +15 & +25 & +33 & +49 & +62 & +59 & +51 & +50 & +70 & +65 & +479 \\
\hline & $7 \%$ & +26 & +31 & +45 & +66 & +66 & +57 & +45 & +56 & +64 & +62 & +518 \\
\hline \multirow[t]{6}{*}{$20^{\circ} \mathrm{C} /$} & $31 \%$ & -43 & -13 & -79 & -85 & -89 & -87 & -82 & -90 & -80 & -76 & -724 \\
\hline & $27 \%$ & -29 & +9 & -20 & -36 & -3 & +1 & -36 & -10 & -30 & -42 & -196 \\
\hline & $21 \%$ & -31 & +17 & +1 & -8 & -16 & +13 & -1 & +19 & +2 & -17 & -21 \\
\hline & $17 \%$ & -19 & +25 & +29 & +55 & +17 & +30 & +61 & +57 & +40 & +63 & +358 \\
\hline & $11 \%$ & +2 & +27 & +38 & +57 & +33 & +62 & +69 & +74 & +61 & +71 & +494 \\
\hline & $7 \%$ & +23 & +44 & +40 & +67 & +40 & +60 & +76 & +60 & +75 & +80 & +565 \\
\hline
\end{tabular}


Tabela 14. Classificação absoluta: pontuações parciais ( $\sum$ das pontuações obtidas nas avaliações fisiológicas por período de armazenamento) e total ( $\sum$ das pontuações parciais) atribuídas aos tratamentos

\begin{tabular}{|c|c|c|c|c|c|c|c|c|c|c|c|c|}
\hline \multirow{2}{*}{\multicolumn{2}{|c|}{$\begin{array}{l}\text { Tratamentos } \\
\text { (temperatura/ } \\
\text { teor de água) }\end{array}$}} & \multicolumn{11}{|c|}{ Período de armazenamento (dias) } \\
\hline & & 35 & 70 & 105 & 140 & 175 & 210 & 245 & 280 & 315 & 350 & Total \\
\hline \multirow[t]{6}{*}{$10^{\circ} \mathrm{C} /$} & $31 \%$ & 47 & 01 & 19 & 13 & 04 & 04 & 00 & 00 & 00 & 00 & 88 \\
\hline & $27 \%$ & 47 & 11 & 35 & 31 & 24 & 28 & 23 & 25 & 20 & 00 & 244 \\
\hline & $21 \%$ & 56 & 27 & 54 & 46 & 46 & 50 & 45 & 44 & 31 & 44 & 443 \\
\hline & $17 \%$ & 74 & 43 & 74 & 72 & 95 & 96 & 76 & 74 & 80 & 88 & 772 \\
\hline & $11 \%$ & 91 & 71 & 91 & 92 & 83 & 64 & 105 & 103 & 89 & 78 & 867 \\
\hline & $7 \%$ & 89 & 86 & 95 & 90 & 103 & 88 & 105 & 114 & 118 & 90 & 978 \\
\hline \multirow[t]{6}{*}{$15^{\circ} \mathrm{C} /$} & $31 \%$ & 26 & 21 & 00 & 02 & 00 & 00 & 00 & 00 & 00 & 00 & 49 \\
\hline & $27 \%$ & 44 & 40 & 27 & 17 & 42 & 18 & 21 & 15 & 00 & 00 & 224 \\
\hline & $21 \%$ & 52 & 62 & 48 & 43 & 63 & 43 & 37 & 40 & 25 & 34 & 447 \\
\hline & $17 \%$ & 62 & 70 & 94 & 69 & 79 & 80 & 66 & 59 & 69 & 84 & 732 \\
\hline & $11 \%$ & 77 & 88 & 87 & 88 & 97 & 91 & 80 & 79 & 96 & 91 & 874 \\
\hline & $7 \%$ & 90 & 82 & 104 & 104 & 103 & 86 & 75 & 79 & 88 & 98 & 909 \\
\hline \multirow[t]{6}{*}{$20^{\circ} \mathrm{C} /$} & $31 \%$ & 20 & 36 & 08 & 08 & 08 & 08 & 03 & 00 & 00 & 00 & 91 \\
\hline & $27 \%$ & 42 & 51 & 26 & 34 & 51 & 50 & 32 & 45 & 34 & 27 & 392 \\
\hline & $21 \%$ & 45 & 72 & 43 & 52 & 45 & 58 & 64 & 66 & 61 & 58 & 564 \\
\hline & $17 \%$ & 44 & 94 & 82 & 90 & 67 & 83 & 99 & 92 & 79 & 89 & 819 \\
\hline & $11 \%$ & 57 & 85 & 77 & 87 & 67 & 91 & 99 & 104 & 95 & 89 & 851 \\
\hline & $7 \%$ & 76 & 99 & 81 & 109 & 72 & 102 & 93 & 92 & 90 & 105 & 919 \\
\hline
\end{tabular}




\section{CONCLUSÕES}

Admitindo os intervalos de $31 \%$ a $7 \%$ de água e de $10^{\circ} \mathrm{C}$ a $20^{\circ} \mathrm{C}$ para 0 armazenamento, a combinação do grau de umidade de $7 \%$ com a temperatura de $10^{\circ} \mathrm{C}$ supera as demais no favorecimento à manutenção do potencial fisiológico das sementes de Passiflora edulis Sims f. flavicarpa Deg. 


\section{REFERÊNCIAS BIBLIOGRÁFICAS}

ALMEIDA, A.M. Maturação e qualidade fisiológica de sementes de maracujá-amarelo (Passiflora edulis f. flavicarpa Deg.). Botucatu, 1985. 91p. Dissertação (M.S.) Faculdade de Ciências Agronômicas, Universidade Estadual Paulista "Júlio de Mesquita Filho".

ALMEIDA, A.M.; NAKAGAWA, J.; ALMEIDA, R.M. Efeito de armazenamento na germinação de sementes de maracujá-amarelo de diferentes estádios de maturação. In: CONGRESSO BRASILEIRO DE FRUTICULTURA, 9., Campinas, 1987. Anais. Campinas: SBF, v.2, 1988. p.603-608.

AGUIAR, I.B.; PINA-RODRIGUES, F.C.M.; FIGLIOLIA, M.B. Sementes florestais tropicais. Brasília: ABRATES, 1993. 350p.

ARAÚJO, E.F.; CORRÊA, P.C.; PEREIRA, O.A. Influência da temperatura de secagem na germinação de sementes de café. Revista Brasileira de Sementes, v.11, n.1/3, p.69-75, 1989.

BARBOZA, R.; HERRERA, J. El vigor en la semilla de café y su relacion com la temperatura de secado, el contenido de humidad y las condiciones de almacenamiento. Agronomia Costarricense, v.14, n.1, p.1-7, 1990.

BECWAR, M.R.; STANWOOD, P.C.; LEONHARDT, K.W. Dehydratation effects on freezing characteristics and survival in liquid nitrogen of desiccation-tolerant and desiccation-sensitive seeds. Journal of the American Society for Horticultural Science, v.108, n.4, p.613-618, 1983. 
BRASIL. Ministério da Agricultura, do Abastecimento e da Reforma Agrária. Regras para análise de sementes. Brasília, 1992. 365p.

BRUCKNER, C.H.; PICANÇO, M.C. Maracujá: tecnologia de produção, pós-colheita, agroindústria, mercado. Porto Alegre: Cinco Continentes, 2001. 472p.

CALIARI, M.F.; SILVA, W.R. Interpretação de dados de testes de vigor na avaliação da qualidade fisiológica de sementes de milho. Revista Brasileira de Sementes, v.23, n.1, p.239-251, 2001.

CARVALHO, A.M. Melhoramento cultural do maracujazeiro. In: SIMPÓSIO CUltURA DO MARACUJÁ, 1., Campinas, 1971. Anais. Campinas: SBF, 1974. p.II 1-9.

CATUNDA, P.H.A.; VIEIRA, H.D.; SILVA, R.F.; POSSE, S.C.P. Influência do teor de água, da embalagem e das condições de armazenamento na qualidade de sementes de maracujá-amarelo. Revista Brasileira de Sementes, v.25, n.1, p.65-71, 2003.

CHAPMAN, T. Passion fruit growing in Kenya. Economic Botany, v.17, n.3, p.165-168, 1962.

COSTA, C.F.; OLIVEIRA, E.L.P.G.; LELLIS, W.T. Durabilidade do poder germinativo das sementes de maracujá. Boletim do Instituto Biológico da Bahia, v.13, n.1, p.7684, 1974.

CROMARTY, A.S.; ELLIS, R.H.; ROBERTS, E.H. Design of seed storage facilities for genetic conservation. Rome: IBPGR, 1985. 100p.

ESQUIVEL, E.A.; LABRADOR, E. Cultivo del maracuya. Chiriqui: Panamá, 1977. 44p.

GERALDI JUNIOR, G. Estudo da germinação de sementes de maracujá-amarelo (Passiflora edulis Sims f. flavicarpa Deg.) armazenado sob duas diferentes condições. Jaboticabal, 1974. 22p. Monografia (Graduação) - Faculdade de Ciências Agrárias e Veterinárias, Universidade Estadual Paulista “Júlio de Mesquita Filho”. 
LIMA, A.A. Por que plantar maracujá? Cruz das Almas: Embrapa, CNPMF, 1993. 2p.

LIMA, D.; BRUNO, R.L.A.; LIMA, A.A.; CARDOSO, E.A. Efeito de recipientes e de dois ambientes de armazenamento sobre a germinação e vigor de sementes de maracujá-amarelo. Revista Brasileira de Fruticultura, v.13, n.2, p.27-32, 1992.

LOPES, P.S.N. Propagação sexuada do maracujazeiro azedo em tubets: efeito da adubação nitrigenada e substratos. Lavras, 1996. 52p. Dissertação (M.S). Universidade Federal de Lavras.

MARCOS FILHO, J.; CICERO, S.M.; SILVA, W.R. Avaliação da qualidade das sementes. Piracicaba: FEALQ, 1987. 230p.

MEDINA, J.C. Maracujá: da cultura ao processamento e comercialização. São Paulo: ITAL, 1980. 207p.

MELETTI, L.M.M.; FURLANI, P.R.; ÁLVARES, V.; SOARES-SCOTT, M.D.; BERNACCI, L.C.; AZEVEDO FILHO, J.A. Novas tecnologias melhoram a produção de mudas de maracujá. O Agronômico, v.54, n.1, p.30-33, 2002.

MELETTI, L.M.M.; SOARES-SCOTT, M.D.; BERNACCI, L.C.; PASSOS, I.R.S. Influência do tratamento térmico em sementes de cinco espécies de maracujá (Passifloraceae). Informativo Abrates, v.13, n.3, p.451, 2003.

NAKAGAWA, J.; CAVARIANI, C.; AMARAL, W.A.N. Armazenamento de sementes de maracujá-amarelo. Revista Brasileira de Sementes, v.13, n.1, p.77-80, 1991.

OLIVEIRA, J.C.; SADER, R.; ZAMPIERI, R.A. Efeito da idade sobre a emergência e vigor de sementes de maracujá-amarelo. Revista Brasileira de Sementes, v.6, n.2, p.37-43, 1984.

PEREIRA, T.S.; ANDRADE, A.C.S. Germinação de Psidium guajava L. e Passiflora edulis Sims - efeito da temperatura, substrato e morfologia do desenvolvimento pósseminal. Revista Brasileira de Sementes, v.16, p.58-62, 1994. 
PEREIRA, K.J.C.; DIAS, D.C.F.S. Germinação e vigor de sementes de maracujá-amarelo (Passiflora edulis Sims f. flavicarpa Deg.) submetidas a diferentes métodos de remoção da mucilagem. Revista Brasileira de Sementes, v.22, n.1, p.288-291, 2000.

PIZA JÚNIOR, C.T. A cultura do maracujá. Campinas: SAA, CATI, 1991. 71p.

SÃO JOSÉ, A.R. Influência do método de extração na qualidade fisiológica de sementes de maracujazeiro amarelo (Passiflora edulis Sims f. flavicarpa Deg.). Botucatu, 1987. 87p. Dissertação (M.S) - Faculdade de Ciências Agronômicas, Universidade Estadual Paulista “Júlio de Mesquita Filho”.

SÃO JOSÉ, A.R.; NAKAGAWA, J. Influência do método de extração na qualidade fisiológica de sementes de maracujazeiro amarelo. In: CONGRESSO BRASILEIRO DE FRUTICUlTURA, 9., Campinas, 1988. Anais. Campinas: SBF, 1988. v.2, p.619-623.

SOUSA, J.S.I.; MELETTI, L.M.M. Maracujá: espécies, variedades, cultivo. Piracicaba: FEALQ, 1997. 179p.

THAI, Y.T. Storage of passion fruit (P. edulis f. flavicarpa) seeds. Malays Agriculture Journal, v.51, n.1, p.18-23, 1977.

TOLEDO, F.F.; MARCOS FILHO, J. Manual das sementes: tecnologia da produção. São Paulo: Agronômica Ceres, 1977. 224p.

VASCONCELOS, L.M.; GROTH, D.; RAZERA, L.F. Efeito de processos de secagem, diferentes graus de umidade e tipos de embalagens na conservação de sementes de café (Coffea arabica L. cv. Catuaí Vermelho). Revista Brasileira de Sementes, v.14, n.2, p.181-188, 1992.

ZAMPIERI, R.A. Efeito da idade sobre a capacidade de emergência e vigor de sementes de maracujá-amarelo (Passiflora edulis Sims f. flavicarpa Deg.). Jaboticabal, 1982. 34p. Monografia (Graduação) - Faculdade de Ciências Agrárias e Veterinárias Universidade Estadual Paulista “Júlio de Mesquita Filho”. 